\title{
Levels of research evidence in health policy assessment in Malawi
}

Patrick Mapulanga and Jaya Raju

Department of Knowledge and Information Stewardship, University of Cape Town, Cape Town, Western Cape, South Africa, and

Thomas Matingwina

Department of Information Science, National University of Science and Technology Zimbabwe, Bulawayo, Zimbabwe

\begin{abstract}
Purpose - The paper examines levels of health research evidence in health policies in Malawi.

Design/Methodology/Approach - The study selected a typology of health policies in Malawi from 2002 to 2017. The study adopted the SPIRIT conceptual framework and assessed the levels of research evidence in health policy, systems and services research using the revised SAGE policy assessment tool. Documentary analysis was used to assess levels of health research evidence in health policies in Malawi.
\end{abstract}

Findings - In 29 (96.7\%) of the health policies, policy formulators including healthcare directors and managers used generic search engines such as Google or Google Scholar to look for heath research evidence. In 28 (93.3\%) of the health policies they searched for grey literature and other government documents. In only 6 (20\%) of the heath policy documents, they used academic literature in a form of journal articles and randomised controlled trials. No systematic reviews or policy briefs were consulted. Overall, in $23(76.7 \%)$ of the health policy documents research evidence played a minimal role and had very little influence on the policy documents.

Research limitations/implications - The empirical evidence in the health policy documents are limited due to insufficient research citation, low retrievability of health research evidence in the policy documents and biased selectivity of what constitutes health research evidence.

Practical implications - The paper indicates that unfiltered information (data from policy evaluations and registries) constitutes majority of the research evidence in health policies both in health policy, systems and services research. The paper seeks to advocate for the use of filtered information (peer reviewed, clinical trials and data from systematic reviews) in formulating health policies.

Originality/value - There is dearth of literature on the levels of health research evidence in health policy-making both in health policy, systems and services research. This study seeks to bridge the gap with empirical evidence from a developing country perspective.

Keywords - SPIRIT, SAGE Assessment tool, Health Policy Assessment, Levels of Research Evidence, Knowledge Translation. 
Paper type - Research paper

\section{Introduction}

The development of any country depends in the improved health status of its people. Findings from health research should play a role in informing policy-making. Over the decades, there has been increased health research expenditure worth of billions of dollars not matching its usage in policy-making in health policy, services and systems research (Grol \& Grimshaw, 2003; Davis, 2006; Graham \& Tetroe, 2007). In North America, over US $\$ 100$ billion are spent yearly on health policy, services and systems research (Brehaut \& Eva, 2012). The United States of America government alone invests nearly US $\$ 32$ billion annually in medical research for the American people (National Institutes of Health, 2014).

In developing countries, various recommendations and strategies have been made on levels of investment in health policy, services and systems research. The World Health Organisation (WHO) has issued several ministerial summit reports on health research and development expenditure such as the Mexico 2004, the Bamako 2008 and the Algiers 2009 declarations on health research (WHO, 2004; 2008; 2009). In part, the declarations state that developing countries would invest at least $2 \%$ of their national expenditures in health research capacity strengthening (WHO, 2004; 2008; 2009). While the target of $2 \%$ of the Gross Domestic Product (GDP) has been difficult for the least developing countries, the expenditure statistics on health budgets indicate that billions of dollars are spent on health research worldwide (Andermann et al., 2016).

However, on average a decade or two elapses before the health research evidence is put into practice, suggesting that there exists a problem gap between health research evidence and its usage in health policy-making (Sussman et al., 2006). Andermann et al. (2016) indicate that the highest quality evidence from health research has no impact unless it is used in policy-making. Health research evidence has little value unless it is put into practice (WHO, 2012). Making use of research evidence in managing health systems, decision and policy-making promises to be a challenge not only for the present but also for decades to come. Partly, healthcare services under healthcare directors and managers in many countries are facing challenges on the use of research 
evidence whose failures have resulted in risks to patient safety and quality of care (Bowen \& Graham, 2013). Walshe and Rundall (2001) outline three categories of healthcare research problems. Firstly, there is the overuse of some health research evidence by healthcare directors, managers, nurses, and medical practitioners where they are not very effective. Secondly, there is the underuse of health research evidence known to be effective but not applied appropriately. Thirdly, there is the misuse of health research evidence even when their effectiveness is unclear.

Evidence matters for health policy-making and the use of health services and systems research could avoid harm and help achieve health policy goals (Parkhurst, 2017). Worldwide, the requirement for policy-making decisions to be based on solid research evidence has received global acknowledgement (Schryer-Roy, 2005). Indications point to the fact that policy-makers including healthcare directors, managers, nurses, and medical practitioners and researchers themselves lack skills, tools and mechanisms to find and use health research evidence to inform policy-making (Lavis et al., 2013). Bartunek et al. (2003) noted that the gap between researchers and policy-makers has been widening partly because research has traditionally been the domain of the academics and medical researchers, many of whom lack knowledge on how to engage health policy-makers, healthcare directors, managers and medical practitioners in their activities. Bartunek et al. further noted that the gap has widened due to several factors; firstly, due to lack of incentives and time needed to establish partnerships between researchers and academics on hand and health policy makers, healthcare directors, managers and medical practitioners on the other hand; secondly, due to strict funding timelines that allows no engagement with policymakers; and thirdly, due to the complexity of activities associated with collaborative research.

\section{Study context}

Malawi is wedged between three countries: Zambia to the northwest, Tanzania to the northeast and Mozambique to the south, southwest and southeast. She has an area of 118,480 square kilometres of which 24,400 square kilometers consists of Lake Malawi. As of 2018, the population was estimated at 18.5 million people. In 2017, Malawi's estimated GDP was around US\$6.26 billion (Statistical Portal Online, 2018). The country's economy is agricultural based, with about $85 \%$ of the population living in rural areas and is one of the least developed countries in the world (IMF Online, 2017). 
Despite its size, Malawi has done some quality health systems and services research through the University of Malawi and other health research partners which has been published in reputable local and international journals and presented at high profile conferences. The University of Malawi colleges namely: Kamuzu College of Nursing and the College of Medicine respectively have been instrumental in conducting health systems and services research in Malawi. Apart from teaching, the major activities of the colleges include: conducting health research activities; supporting the conduct of clinical trials; disseminating health research results to faculty members; and, coordinating the dissemination of health research findings through different communication channels to various health stakeholders (College of Medicine, University of Malawi, 2015).

Health policy and systems research is regulated by the National Commission for Science and Technology with delegated responsibilities for health services research to the College of Medicine Research and Ethics Committee (African Health Observatory Online, 2015). Despite these review boards, the conduct of health research in Malawi lacks mechanisms for coordination, regulation and appropriate structures to support health research evidence (African Health Observatory Online, 2015). One of the weaknesses of the system has been weak linkages between various health research data sources and lack of data triangulation centres (Kirigia et al., 2015).

\section{Theoretical framework}

This study was based on the SPIRIT Action Framework (see Figure 1) which describes steps, barriers, facilitators and contextual use of health research evidence in policy-making. The framework suggests that policy-making is influenced by many factors such as the public opinion, media, members of the legislature, political ideologies and priorities, stakeholders interests, experts advice (healthcare directors, managers and medical practitioners) and many other aspects

(Makkar et al., 2016). The SPIRIT framework posits that once research is involved in the policy formulation, policy-makers initiate several steps in searching, obtaining, appraising the quality of research evidence in support of the policy. Sometimes they interact with researchers to obtain or generate relevant research evidence (Makkar et al., 2016). 


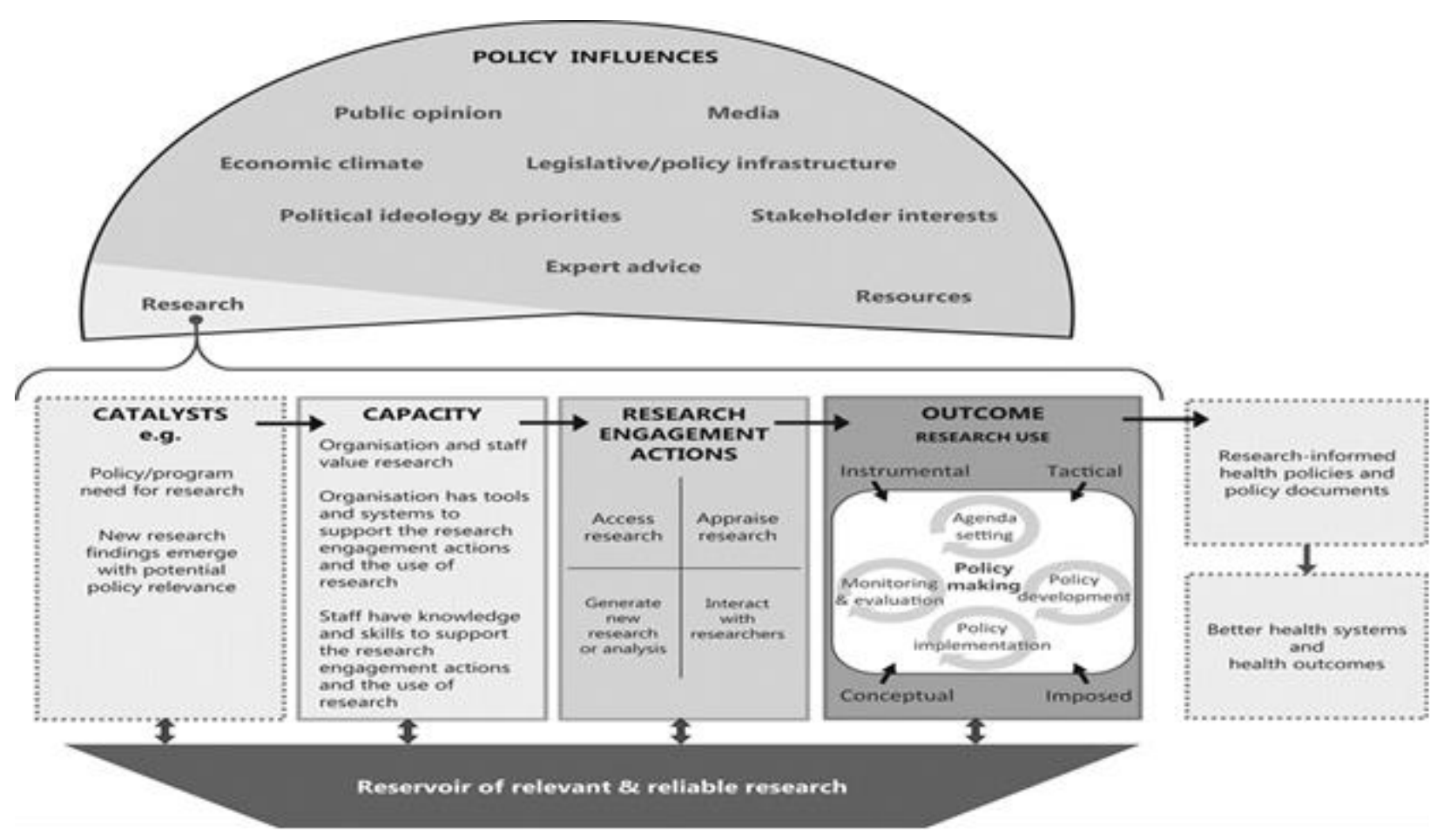

Figure 1: SPIRIT framework, Source: Redman, et al. (2015)

Once research has been obtained it is used to inform policy in four major ways: firstly, research evidence directly influences priority issues or decisions to be made (instrumental); secondly, research evidence may provide ideas, the understanding or concepts to clarify thinking about the policy issues and therefore indirectly influencing the policy content (conceptual); thirdly, research evidence may justify or exert weight on the pre-existing decisions and courses of action or make a case for policy changes to be made to the existing policies (tactical); and fourthly, research evidence may be used to meet organisational, legislative or funding requirements to the use of health research evidence (imposed) (Makkar et al., 2016).

However, the framework postulates that there are: firstly, barrier or facilitators to the use of research evidence; secondly, individual factors to the use of health research evidence such as skills in accessing and applying heath research evidence; thirdly, external pressure from the media, stakeholder's interests including the availability of resources; and fourthly, organisational setups including tools and equipment to support research use (Makkar et al., 2016).

\section{Research methodology}


The study adopted the document analysis methodology. Document analysis is a form of research in which documents are interpreted by the researcher to give them meaning around a topic under study (Bowen, 2009; O'Leary, 2014). The study identified health policies in Malawi from 19922017. The year 1992 co-incided with the opening of the College of Medicine. The study thereafter carried out a document analysis of the 30 health policies in Malawi to examine their levels of evidence using a Staff Assessment of enGagement with Evidence (SAGE) tool checklist. Data was analysed used descriptive statistics and presented using graphs and charts. Table 1 captures the processes of selecting health policies in Malawi from 1992 to 2017.

\section{Table 1: Steps of identifying health policies in Malawi}

\begin{tabular}{|c|c|}
\hline $\begin{array}{l}\text { Identification of a sample of } \\
\text { health policies in Malawi }\end{array}$ & $\begin{array}{l}\text { - Selected or created a typology of health policies } \\
\text { - Identified health policies from each policy category } \\
\text { using available sources } \\
\text { - Selected health policies in each category } \\
\text { - Assessed the representativeness of the selected health } \\
\text { policies across dimensions not covered by the } \\
\text { typology }\end{array}$ \\
\hline $\begin{array}{l}\text { Identification of health } \\
\text { research use by stage of the } \\
\text { health policy-making } \\
\text { process in Malawi }\end{array}$ & $\begin{array}{l}\text { Determined what constitutes health research } \\
\text { evidence } \\
\text { - Identified explicit uses of citable health research } \\
\text { evidence } \\
\text { - Assessed explicit uses of citable health research } \\
\text { evidence } \\
\text { - Identified explicit uses of other types of health } \\
\text { information (which may or may not be based on } \\
\text { research) }\end{array}$ \\
\hline $\begin{array}{l}\text { Identification of } \\
\text { circumstances under which } \\
\text { health research evidence was } \\
\text { used (by stage of the policy- } \\
\text { making process) }\end{array}$ & $\begin{array}{l}\text { Identified non-explicit uses of health research } \\
\text { evidence } \\
\text { - Identified factors that influence the health policy- } \\
\text { making process } \\
\text { - Identified factors that exert a major influence on the } \\
\text { health policy-making process }\end{array}$ \\
\hline
\end{tabular}

Adapted from: Lavis et al. (2002).

Due to poor record keeping the study was only able to access some print and electronic healthrelated policies from 2002 to 2017. A total of 30 health-related policies were selected for presentation and analysis based on how research evidence was used in their formulation (see 
Table 2). Using the SPIRIT Framework, a modified tool to the SAGE interview schedule, was used for the document analysis to evaluate how health policy-makers in Malawi engaged with health research evidence. The tool examined how health research evidence is appraised, generated and how health policy-makers use such health research evidence. The tool also assessed levels of barriers to the use of health research evidence in health policy formulation.

Table 2: Policies in each category

\begin{tabular}{|c|c|c|c|c|c|}
\hline Category & Policy Title & $\begin{array}{l}\text { Document } \\
\text { type }\end{array}$ & Status & Period & \\
\hline \multirow[t]{4}{*}{$\begin{array}{l}\text { Planning \& Policy } \\
\text { Development }\end{array}$} & National Health Finance Strategy & Strategy & Approved & $\begin{array}{l}2011- \\
2016 \\
\end{array}$ & \\
\hline & $\begin{array}{l}\text { National Health Research } \\
\text { Agenda }\end{array}$ & Strategy & Approved & $\begin{array}{l}2012- \\
2016 \\
\end{array}$ & $\begin{array}{l}2017- \\
2022\end{array}$ \\
\hline & Health Sector Strategic Plan & Plan & Approved & $\begin{array}{l}2011- \\
2016\end{array}$ & \\
\hline & $\begin{array}{l}\text { Malawi National eHealth } \\
\text { Strategy }\end{array}$ & Strategy & Approved & $\begin{array}{l}2011- \\
2016 \\
\end{array}$ & \\
\hline $\begin{array}{l}\text { Central Monitoring } \\
\text { \& Evaluation }\end{array}$ & $\begin{array}{l}\text { National Health Information } \\
\text { System Policy }\end{array}$ & Policy & Approved & $2015-$ & \\
\hline \multirow{2}{*}{$\begin{array}{l}\text { Health Education } \\
\text { Services }\end{array}$} & Health Promotion Policy & Policy & Approved & $2014-$ & \\
\hline & National Sanitation Policy & Policy & Approved & 2006- & \\
\hline \multirow{3}{*}{$\begin{array}{l}\text { National Malaria } \\
\text { Control Programme }\end{array}$} & National Malaria Policy & Policy & Approved & $2002-$ & \\
\hline & Malaria Strategic Plan & Plan & Approved & $\begin{array}{l}2005- \\
2010\end{array}$ & $\begin{array}{l}2011- \\
2015\end{array}$ \\
\hline & $\begin{array}{l}\text { Malaria Communication } \\
\text { Strategy for Malawi }\end{array}$ & Strategy & Approved & $\begin{array}{l}2009- \\
2014\end{array}$ & $\begin{array}{l}2015- \\
2020\end{array}$ \\
\hline \multirow[t]{4}{*}{$\begin{array}{l}\text { Environmental } \\
\text { Health }\end{array}$} & $\begin{array}{l}\text { Infection Control \& Waste } \\
\text { Management Plan for Malawi }\end{array}$ & Plan & Approved & 2016- & \\
\hline & $\begin{array}{l}\text { National Environmental Health } \\
\text { Policy }\end{array}$ & Policy & Approved & $2011-$ & \\
\hline & $\begin{array}{l}\text { Health Care Waste Management } \\
\text { Policy \& Strategic Plan }\end{array}$ & $\begin{array}{l}\text { Policy \& } \\
\text { Plan }\end{array}$ & Approved & $2004-$ & 2016- \\
\hline & $\begin{array}{l}\text { Infection Control \& Waste } \\
\text { Management Plan for Malawi }\end{array}$ & Plan & Approved & $2016-$ & \\
\hline \multirow[t]{2}{*}{$\begin{array}{l}\text { National TB Control } \\
\text { Programme }\end{array}$} & $\begin{array}{l}\text { Malawi Policy on TB Control in } \\
\text { Prisons }\end{array}$ & Policy & Approved & $2012-$ & \\
\hline & $\begin{array}{l}\text { National TB Control Programme } \\
\text { Strategic Plan }\end{array}$ & Plan & Approved & $\begin{array}{l}2012- \\
2016\end{array}$ & \\
\hline Nursing Services & $\begin{array}{l}\text { National Community Home } \\
\text { Based Care Policy \& Guidelines }\end{array}$ & Policy & Approved & $\begin{array}{l}2005- \\
2010\end{array}$ & \\
\hline
\end{tabular}




\begin{tabular}{|c|c|c|c|c|c|}
\hline & National Palliative Care Policy & Policy & Approved & $2014-$ & \\
\hline \multirow[t]{3}{*}{ Clinical Services } & National Alcohol Policy & Policy & Approved & $2015-$ & \\
\hline & Injection Safety Policy & Policy & Approved & $2004-$ & \\
\hline & National Nutrition Policy & Policy & Approved & & \\
\hline \multirow[t]{2}{*}{ HIV \& AIDS } & National HIV/AIDS Policy & Policy & Approved & $2004-$ & \\
\hline & $\begin{array}{l}\text { Strategy for the Health Sector } \\
\text { Response to HIV/AIDS in } \\
\text { Malawi }\end{array}$ & Strategy & Approved & 2003 & \\
\hline \multirow[t]{2}{*}{$\begin{array}{l}\text { Reproductive Health } \\
\text { Unit }\end{array}$} & $\begin{array}{l}\text { National Sexual \& Reproductive } \\
\text { \& Rights Policy }\end{array}$ & Policy & Approved & 2009 & \\
\hline & $\begin{array}{l}\text { Reproductive Health Strategic } \\
\text { Plan }\end{array}$ & Plan & Approved & $\begin{array}{l}2006- \\
2011\end{array}$ & \\
\hline \multirow[t]{3}{*}{ Diagnostics services } & National Medicines Policy & Policy & Approved & 1991- & \\
\hline & $\begin{array}{l}\text { Malawi Standards Treatment } \\
\text { Guidelines }\end{array}$ & Guidelines & Approved & $\begin{array}{l}2009- \\
2014\end{array}$ & 2015 \\
\hline & Malawi Essential Medicines List & List & Approved & $2009-$ & \\
\hline
\end{tabular}

\section{Study findings}

Figure 2 shows sources of health-related policies analysed. Twenty-seven (27 or 90\%) of the health-related policies identified were from the Ministry of Health while one (1 or 3\%) each were from the Ministries of Economic Planning, Irrigation and Water Development and the Office of the President and Cabinet, respectively. 


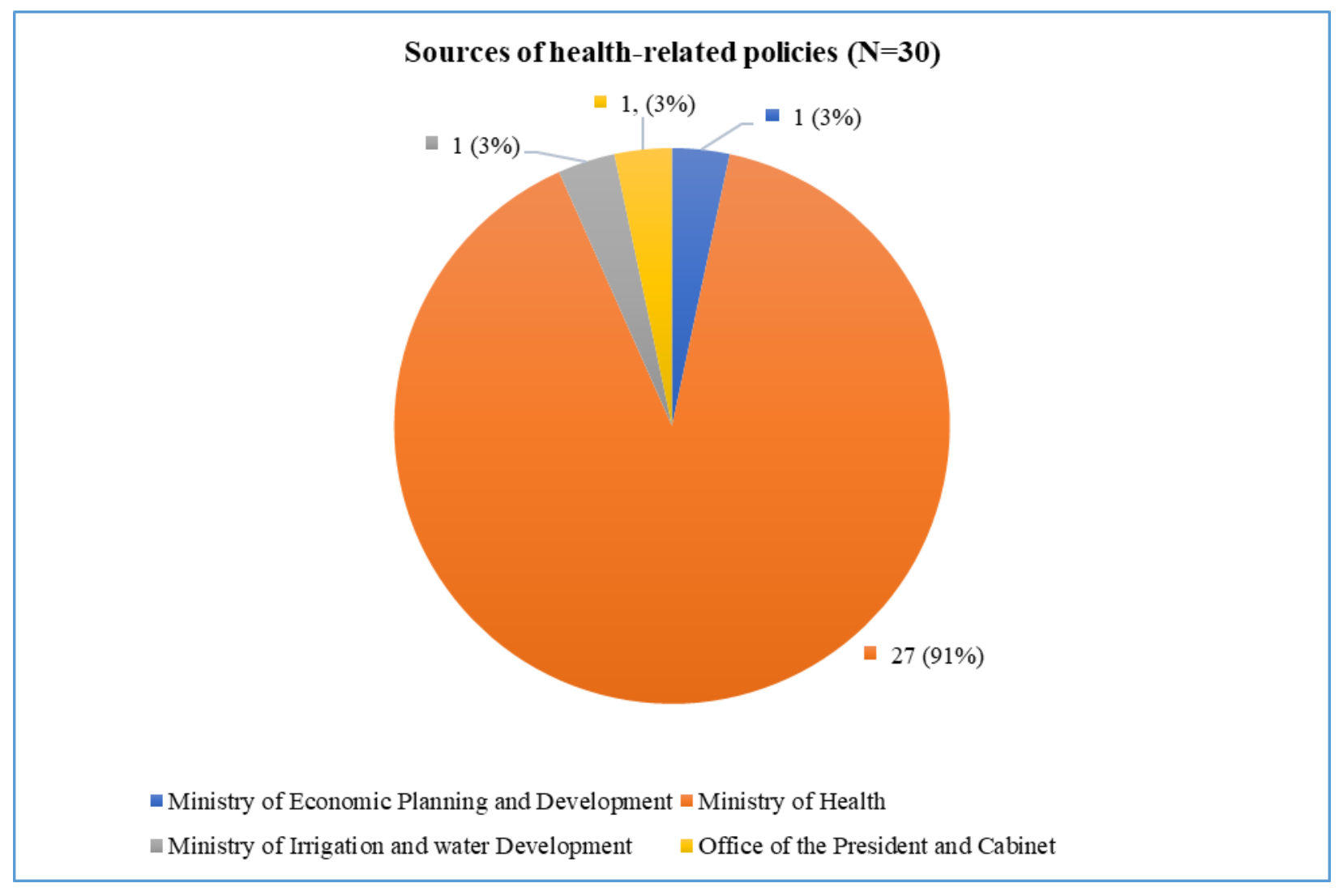

Figure 2: Sources of health policies

\section{Role of Ministry in health policy formulation}

Figure 3 shows the various roles played by ministries in the health policy formulation. Central role suggests that the health policy-makers, healthcare directors and managers developed the health policy document themselves. Marginal role refers to the health policy-makers, healthcare directors and managers contributing towards the policy documents while advisory role indicates that the health policy-makers directed the process of policy document as well (Makkar et al., 2016). Figure 3 implies that out of $26(86.7 \%)$ and $28(93.3 \%)$ of the health policies formulated, ministries played advisory and central roles during formulation. The central role was a result of the Malawi government's commitment to fulfil international agreements, obligations and declarations. For example, the National Palliative Care Policy was a response to the 2002 Cape Town Declaration; the 2003 Palliative Care Conventions; the 2005 Korea Declaration; and, the 2013 African Ministers of Health session on Palliative Care. Locally, the Ministry of Health was 
also responding to the 2011-2016 Malawi Health Sector Strategic Plan, Malawi Vision 2020 and the 2011-2016 Malawi Growth and Development Strategy II.

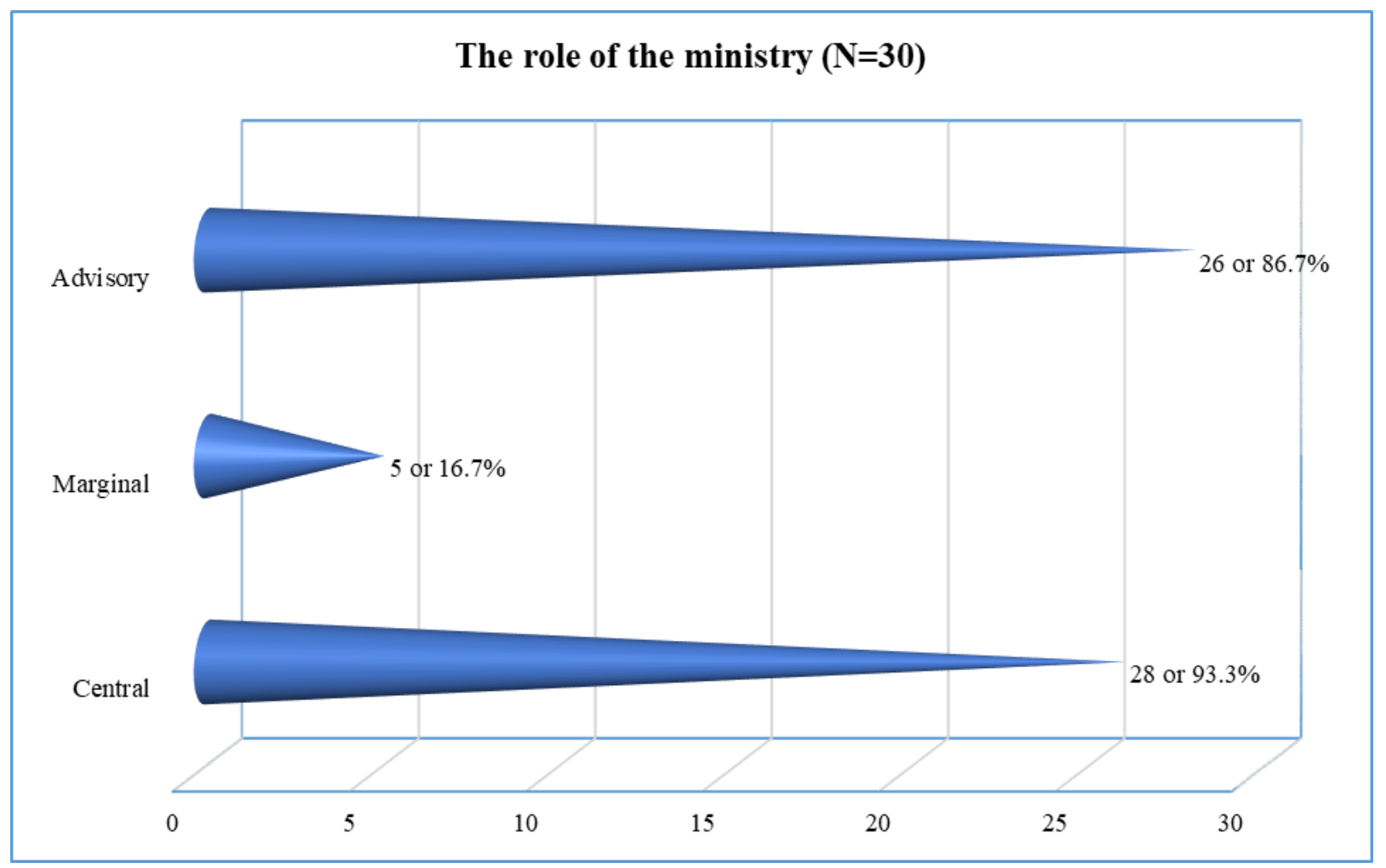

\section{Figure 3: Role of the ministry in policy formulation}

Regarding the Malaria Policy, the Government played both central and advisory roles in response to the Roll Back Malaria agreement at the Abuja Declaration signed by Heads of State in 2000. Further, the National Alcohol Policy conformed with the World Health Assembly, and the African Ministers of Health commitment to reducing the harmful use of alcohol. The alcohol policy was a commitment to the WHO's Global Action Plan on the prevention and control of non-communicable diseases.

How research informed the formulation of health policy documents

Health research evidence that informed policy formulation can be either be systematic or serendipitous involving broad and rigorous searches or narrow and limited searching (Makkar et al., 2016). Figure 4 shows methods of searching for health research evidence. Document analysis of the policies shows that both primary studies (journal articles) and secondary studies (textbooks) were missing in the policy documents. 


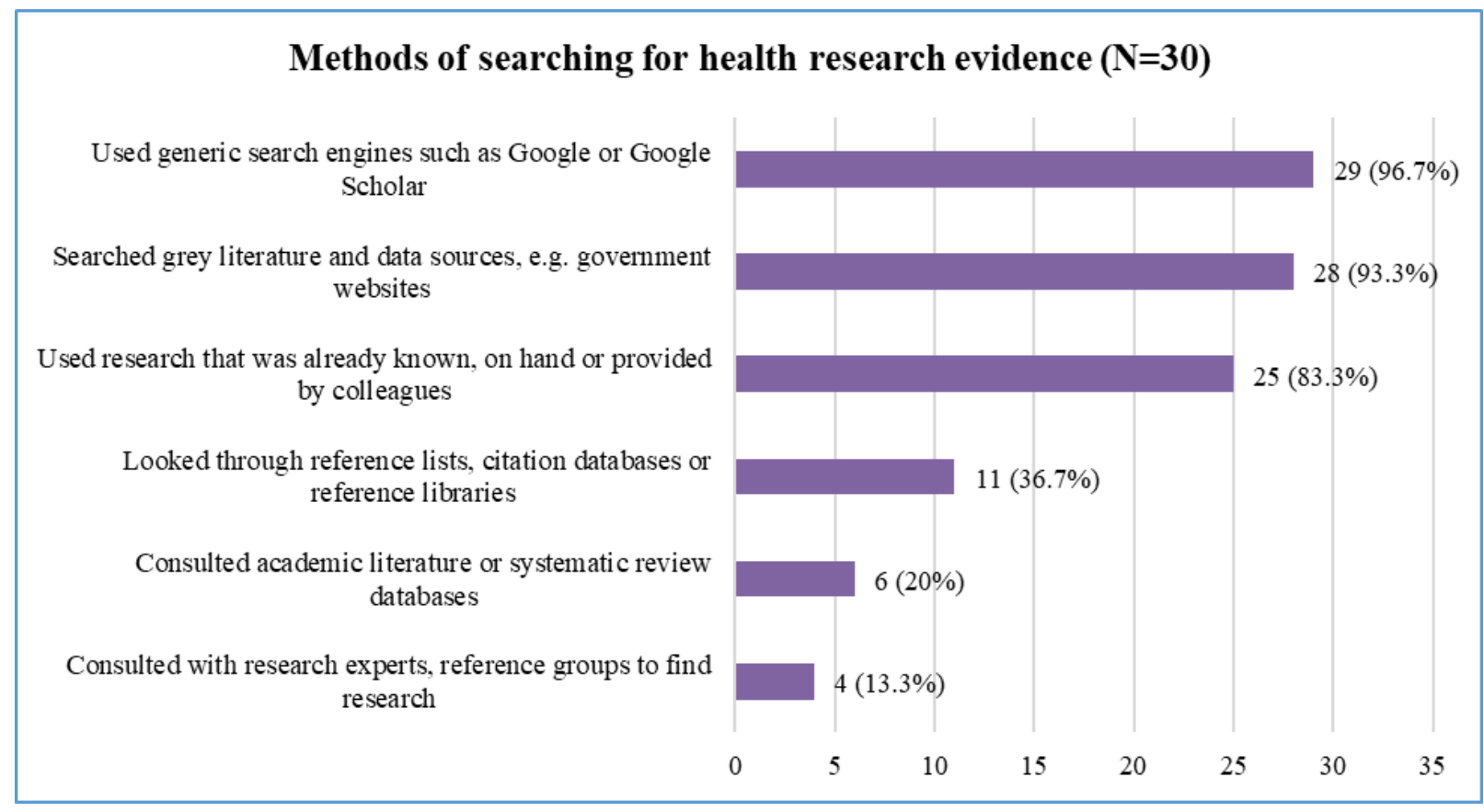

\section{Figure 4: Methods of searching for health research evidence}

In $29(96.7 \%)$ of the 30 health policies, the directors at the Ministry of Health, healthcare directors and managers used generic search engines such as Google or Google Scholar to look for heath research evidence. In 28 (93.3\%) of the health policies they searched for grey literature and other government documents. In only $6(20 \%)$ of the health policies did the directors at the ministry, healthcare directors and managers use academic literature in the form of journal articles and randomised controlled trials. Document analysis of the selected health policies shows that no systematic reviews or policy briefs were consulted. Basic health research evidence used ranged from the use of data from the National Statistical Office, WHO, Google or grey literature from government websites.

\section{Types of research found in health policies}

Types of academic documents include journals, systematic reviews; technical monographs or textbooks; government reports, other unpublished grey literature or data from registries (Makkar et al., 2016). Figure 5 shows types of health research evidence found in the health policies examined in Malawi. 


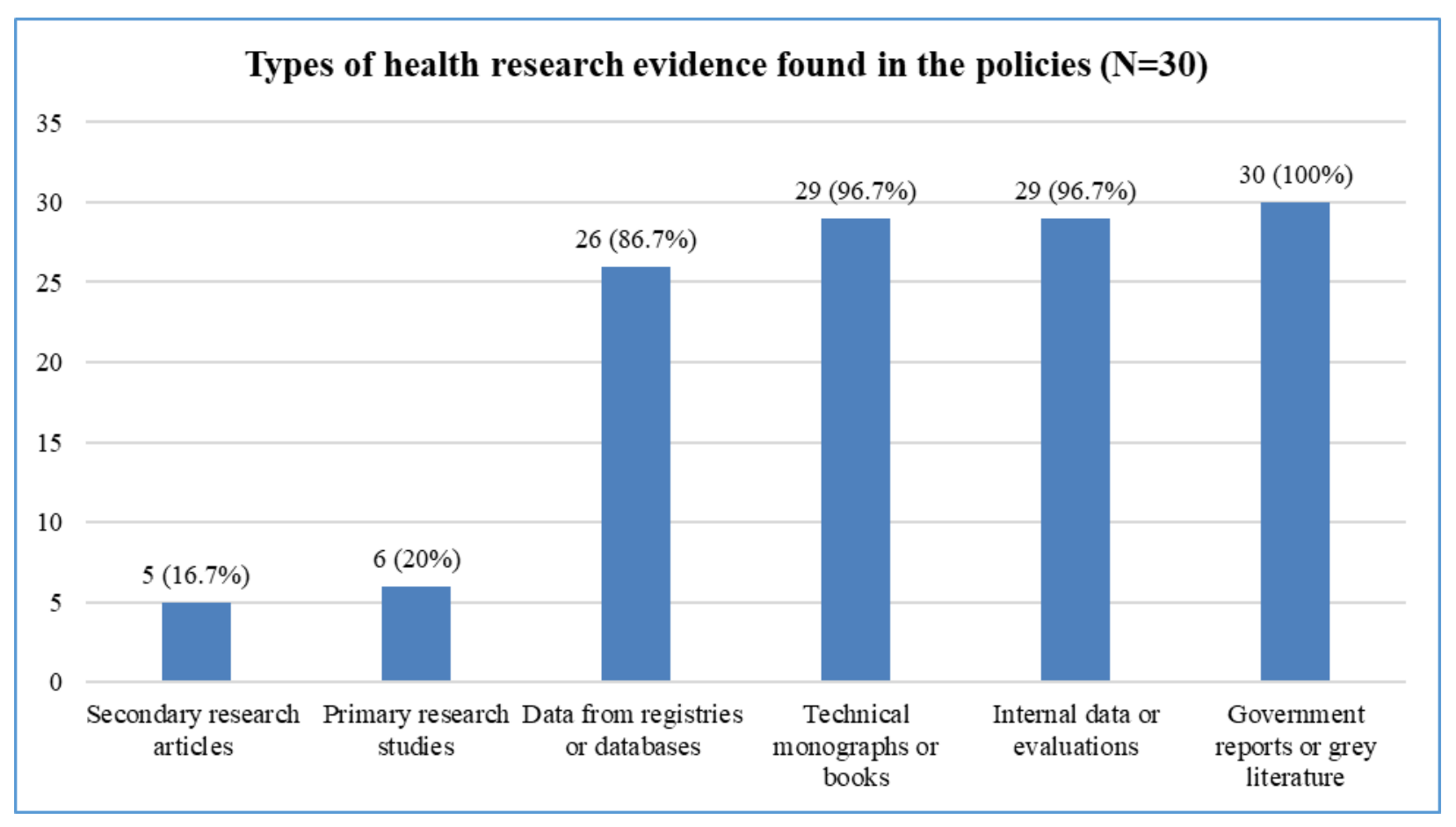

Figure 5: Types of research data found in health policies

Figure 5 shows that in $5(16.7 \%)$ of the 30 health policy documents the directors at the ministry, healthcare directors and managers used secondary research articles such as research summaries. In $6(20 \%)$ of the health policy documents they used primary research in the form of trials and published journals. No evidence of systematic reviews was encountered during the analysis of the bibliographical references of the policy documents. Instead, health policy documents used technical monographs from the ministries and the National Statistical Office (29 or 96.7\%); government reports including evaluations of previous health policies or programmes (30 or $100 \%)$; internal data or evaluations within the ministries $(96.7 \%)$ or data from ministry registries (26 or 86.7\%). Document analysis of the 30 health policies shows that government reports and unpublished police reports were mostly used simply to provide the context of the health policy problem. Other than that, there were not feasible actionable messages such as policy briefs of health research evidence. 


\section{Relevance of the research found in health polices}

Relevance examined the concepts of appropriateness of the health research evidence in the health policies and their application to the policy context (Makkar et al., 2016). Figure 6 shows the relevance of the health research evidence within the policy context.

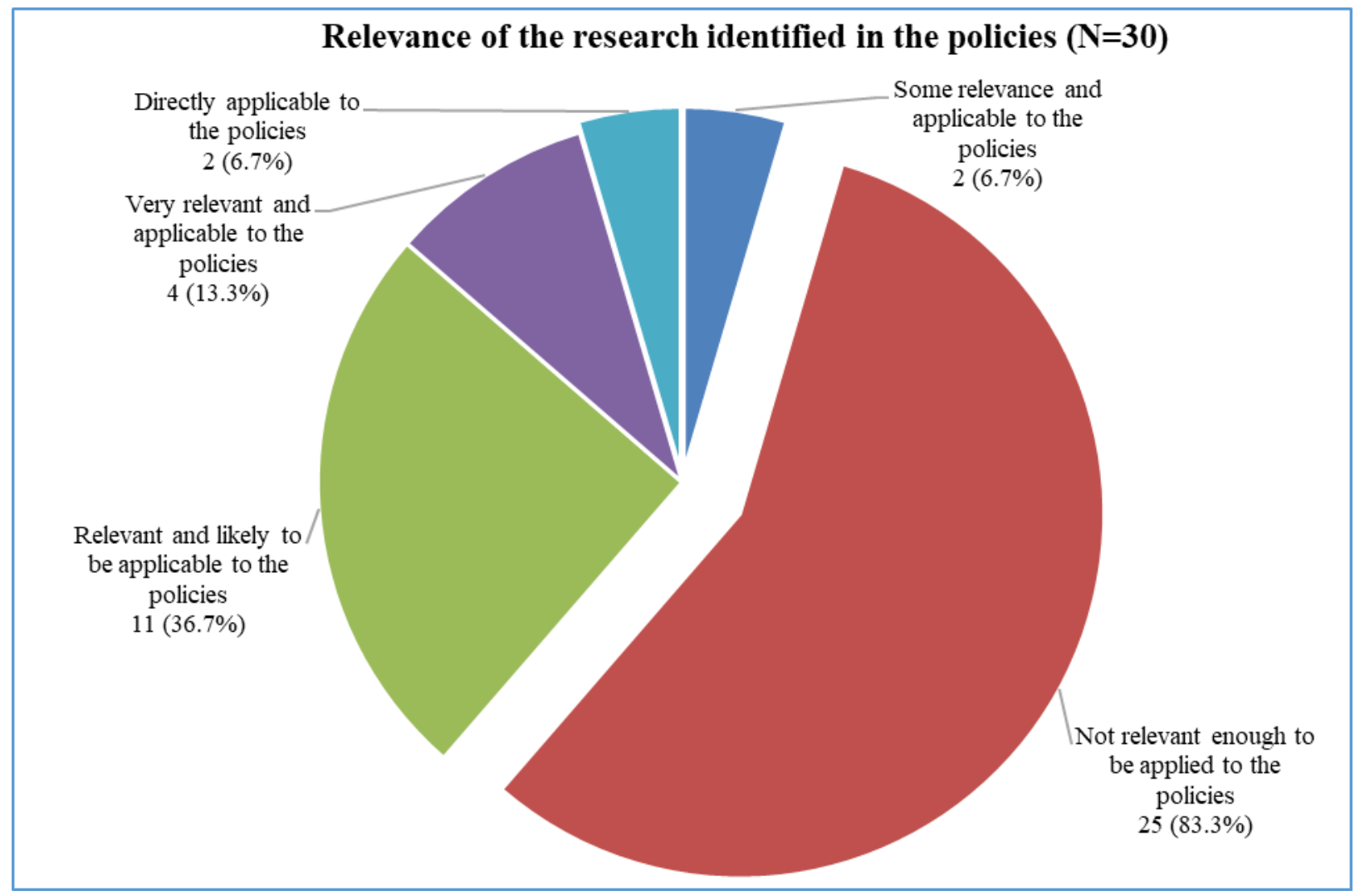

Figure 6: Relevance of the research found in health policies

In $25(83.3 \%)$ of the 30 health policies the research evidence was not relevant enough to be applied to the health policy context. In $4(13.3 \%)$ of the health policies relevant documents were used for the policy context. In only $2(6.7 \%)$ of the health policies was health research evidence directly applicable to the health policy documents. Document analysis of the health policy documents shows that in only $2(6.7 \%)$ of the health policy documents, health research evidence was directly applicable to the health policy documents and the research evidence came from the use of randomised controlled trials and peer reviewed journal articles. 
The assessment of the health research evidence was at four levels as suggested by Makkar et al. (2016) namely: applicability of the health research evidence to policy context; use of the actionable or feasible health research evidence; consistency of the health research evidence with the previous research; and, compatibility with organisational values or knowledge. Figure 7 shows the assessment levels for the health research evidence found in the policy documents.

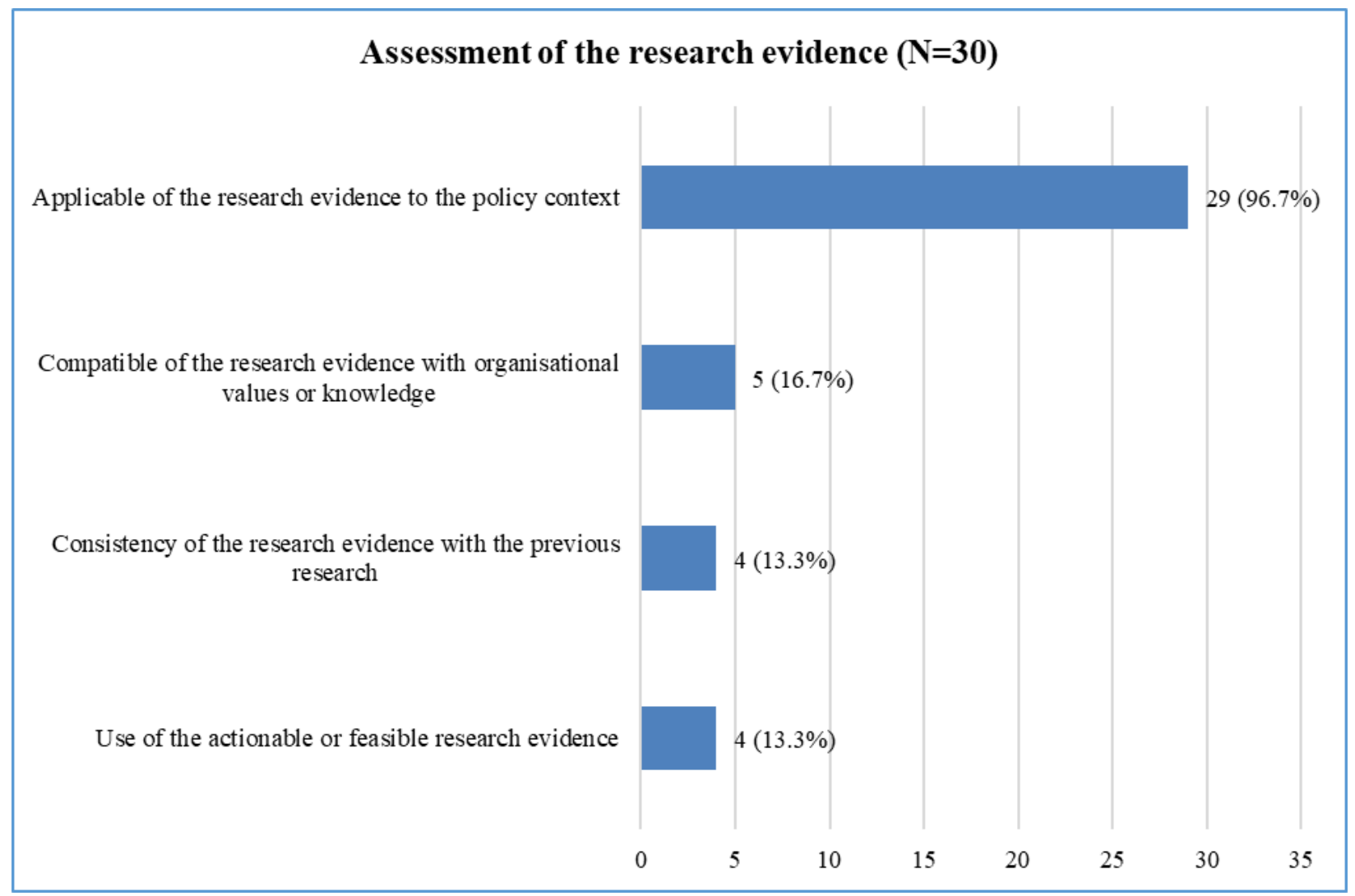

\section{Figure 7: Assessment of research evidence}

In $4(13.3 \%)$ of the 30 health policy documents the research evidence was consistent with the previous research especially from the National Statistical Office, other government documents and research summaries. In 29 (96.7\%) of the policy documents, the research evidence was applicable to the health policy documents. However, no actionable documents such as policy briefs and systematic reviews were referred to in the health policy documents. 


\section{Quality of the health research evidence}

Quality suggests that the research design was robust enough to lead to accurate conclusions. In the absence of systematic reviews informing the health policies, the available health research evidence was weighed in terms of sample size sufficiency, methods of collecting data and how validity issues were addressed (Makkar et al., 2016). Figure 8 shows the outcome of the quality assessment of health research evidence.

\section{Quality of health research evidence $(\mathrm{N}=30)$}

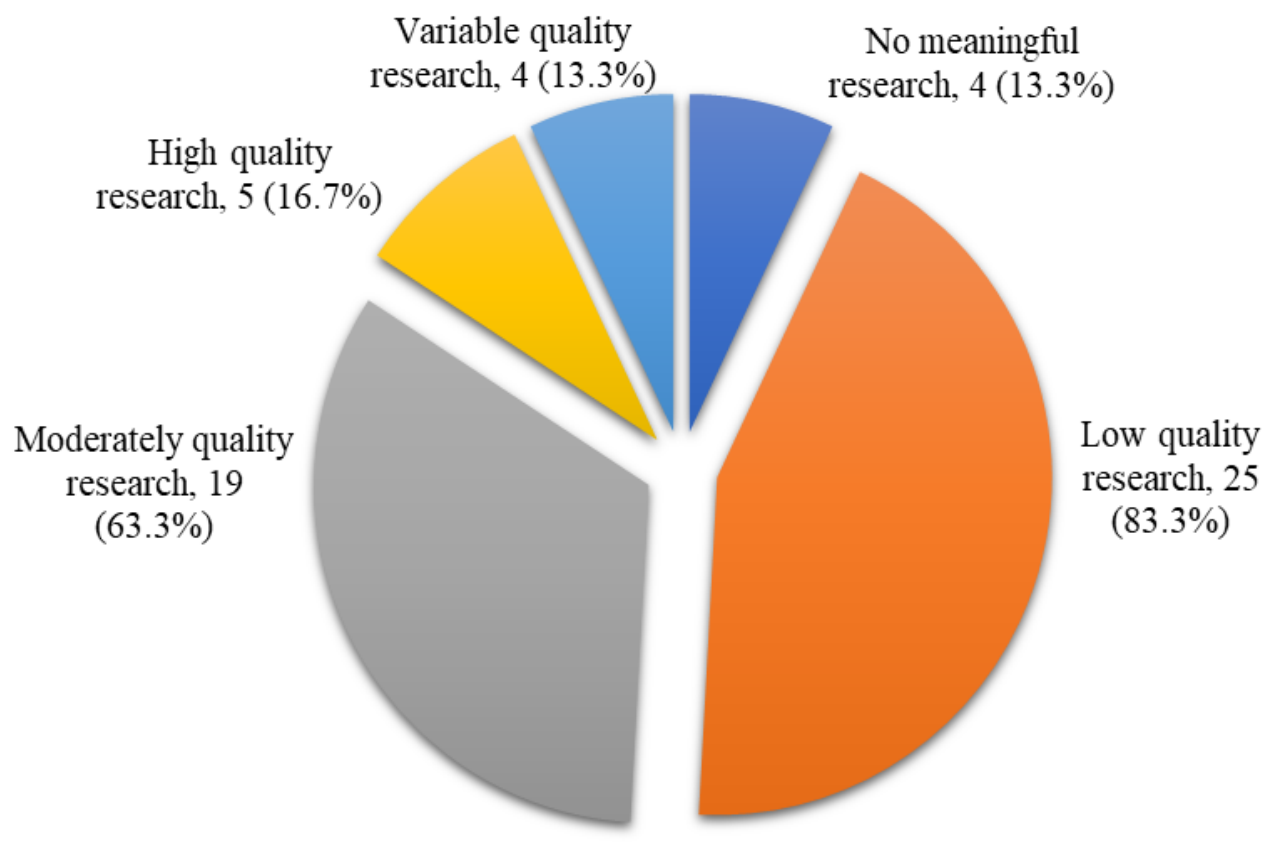

\section{Figure 8: Quality of health research evidence}

In $4(13.3 \%)$ each of the 30 health policy documents there was no meaningful health research evidence and the quality varied considerably. In 25 (83.3\%) of the health policies there was low quality health research evidence which relied heavily on internal data from the ministry registries, grey literature from ministry research summaries and reports from the National Statistical Office. Only 5 (16.7\%) of the health policy documents showed the use of primary research studies such as peer reviewed journal articles and randomised controlled trials. 
The policy-making culminates into a consultative process which involves various personnel such as academics and researchers, healthcare directors, managers, medical practitioners and employ some strategies (Makkar et al., 2016). Figure 9 shows the forms of consultations for the health policy formulation $(\mathrm{N}=30)$.

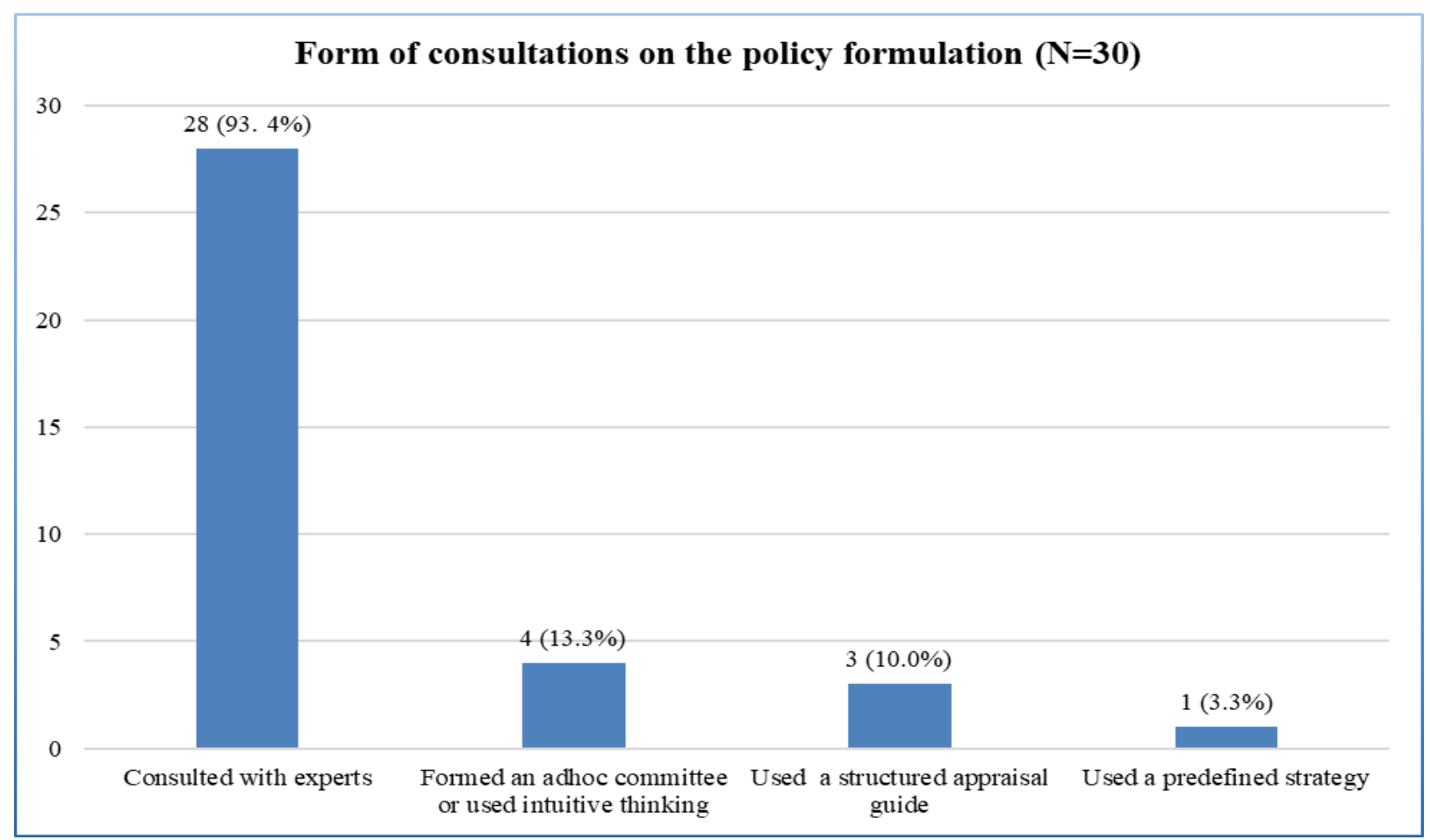

\section{Figure 9: Form of consultations for the policy formulation}

In $28(93.4 \%)$ of the 30 health policies, health subject experts both in the academia and clinical sites (healthcare directors and managers) were consulted and formulated the health policies. In 3 (10\%) of the health policy documents, policy formulators including healthcare directors and managers used a structured appraisal of evidence. In 4 (13.3\%) of the health policy documents, there were no references to sources of evidence which suggests that they were formulated adhoc or intuitively using policy-makers institutional memory rather than any health research evidence. In some cases, experts consulted each other for direction on policy formulation outside the use of health research evidence. 
Methods of examining the research evidence include: intuitive processes, specific criteria, evaluating evidence adhoc, or the use of heath experts (Makkar et al., 2016). Figure 10 shows the evaluation of the quality of health research evidence.

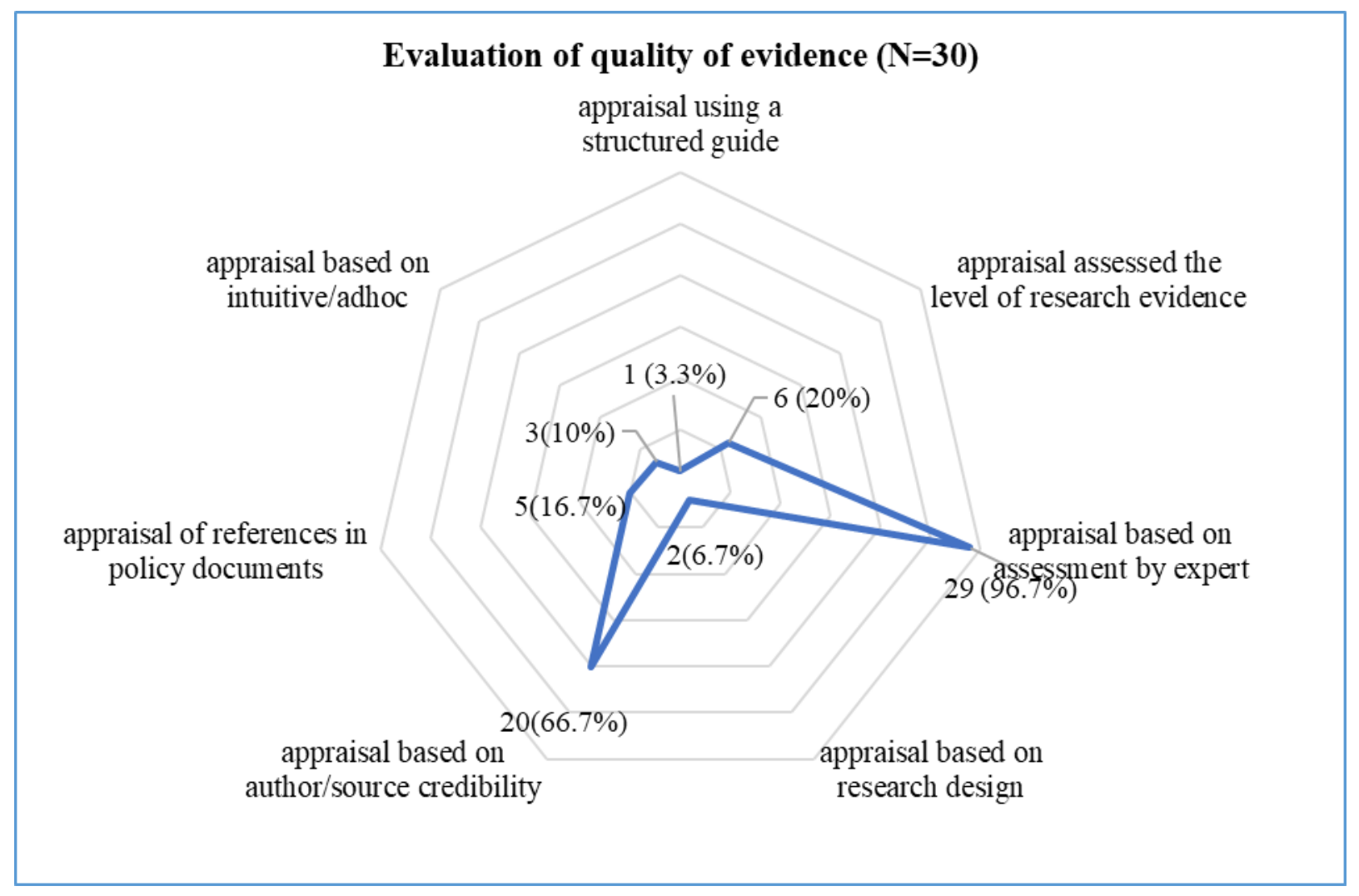

\section{Figure 10: Methods of soliciting health research evidence}

In $29(96.7 \%)$ and $20(66.7 \%)$ of the 30 health policy documents, appraisal of evidence was based on health expert opinion and author or source of credibility, respectively. In 5 (16.7\%) of the health policy documents appraisal of health research evidence was based on references in other policy documents. In only $2(6.7 \%)$ of the policies appraisal it was based on the research design such as randomised controlled design while in $6(20 \%)$ the appraisal was based on the levels of health research evidence such as peer reviewed journals. 
Health policy formulation involves working groups some of which include health experts, researchers, clinicians, practitioners, healthcare managers and directors (Makkar et al., 2016). Figure 11 shows the type of personnel involved in health policy formulation in Malawi.

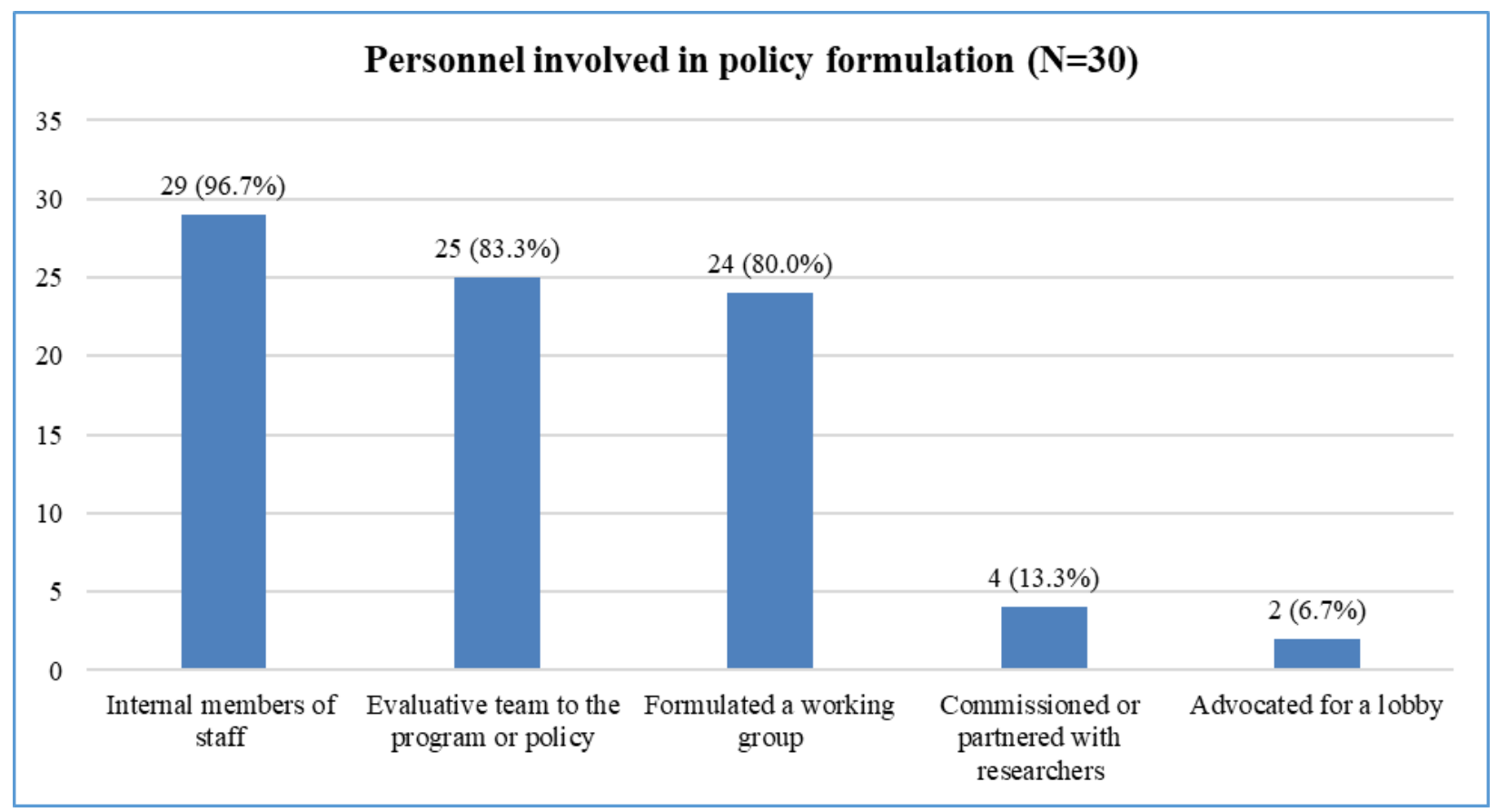

\section{Figure 11: Type of personnel involved in health policy formulation}

In $29(96.7 \%)$ of the 30 policy documents, directors at the ministry, healthcare directors and managers involved internal members of staff within the ministries. In $25(83.3 \%)$ of the health policies an evaluative team within the ministry was established. In $24(80 \%)$ of the policies a working group was formulated. In only $4(13.3 \%)$ of the policy documents directors at the ministry, healthcare directors and managers partnered with health researchers and academics in designing the health policy documents.

\section{How research informed the development of the policy document}

Research use in health policy formulation can be effected at four levels, namely: instrumentally, conceptually, tactically or it can be imposed on the policy itself or the processes (Makkar et al., 2016). These four levels informed the type of research evidence use in Malawi: 


\section{Conceptual use of research evidence}

Conceptual use of research is derived when the research evidence itself provides indirect knowledge for understanding the policy formulation processes and helped directors at the ministry, healthcare directors and managers to grasp issues that may influence their thinking but without documentable or direct impact (Makkar et al., 2016). This includes health research evidence informing the background thinking about the design, conduct, evaluation, selection of outcomes and, development of the evaluation tools for the policy formulation processes. Figure 12 shows how health research evidence conceptually informed health policy formulation in Malawi.

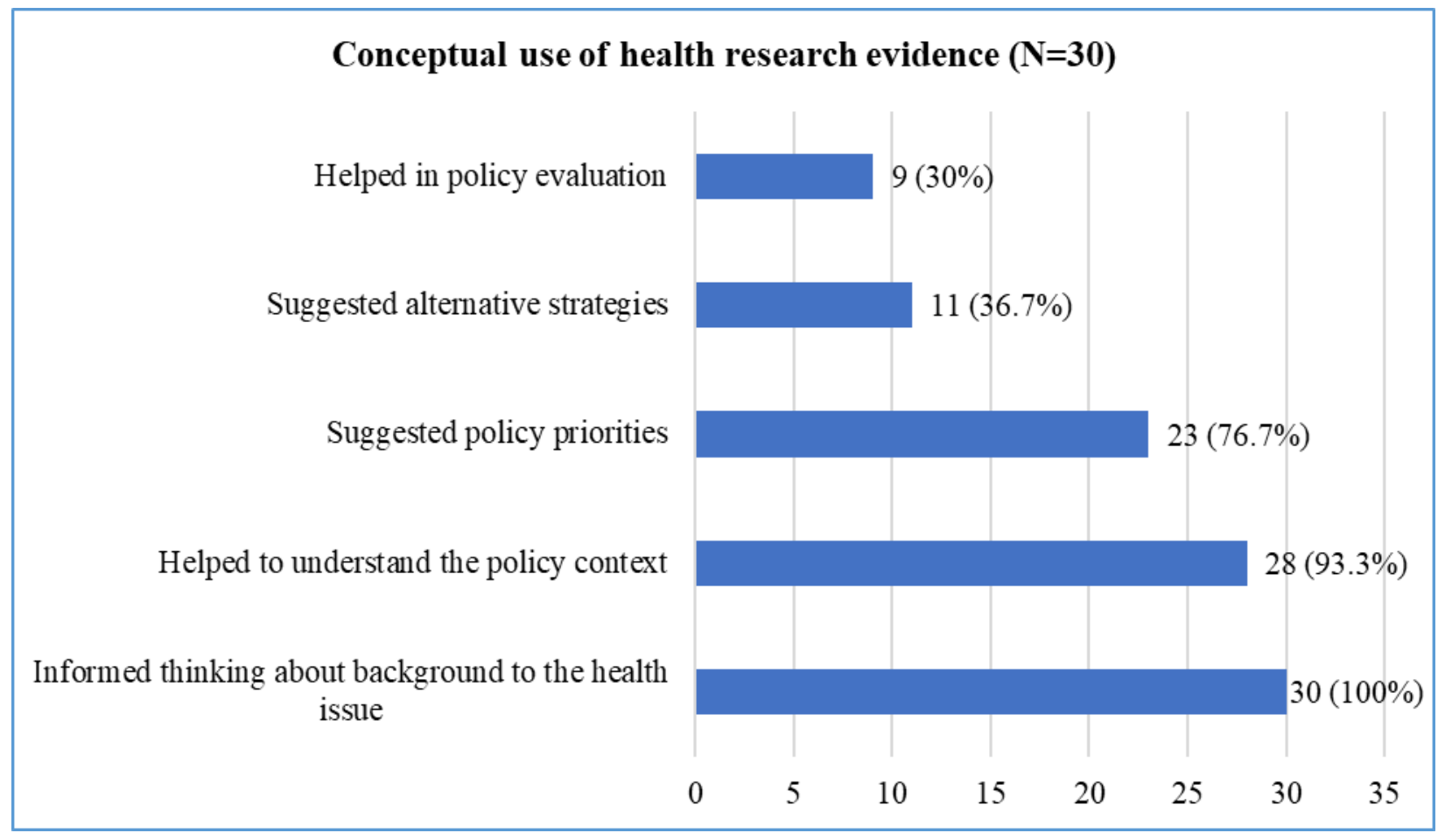

\section{Figure 12: Conceptual use of health research in policy formulation}

In all $30(100 \%)$ of the health policy documents analysed, research informed thinking about the health policy issues. In $28(93.3 \%)$ of the health policy documents research helped the directors at the ministry, healthcare directors and managers to understand the policy context. 
Instrumental use of health research evidence entails the use of health research evidence to provide knowledge of action that informs policy decisions and directly informs the policy content (Makkar et al., 2016). This includes the use of health research evidence in determining the policy evaluation methods, selection of policy outcomes or the identification of existing policy tools for usage. Figure 13 shows the instrumental use of health research evidence use in Malawi.

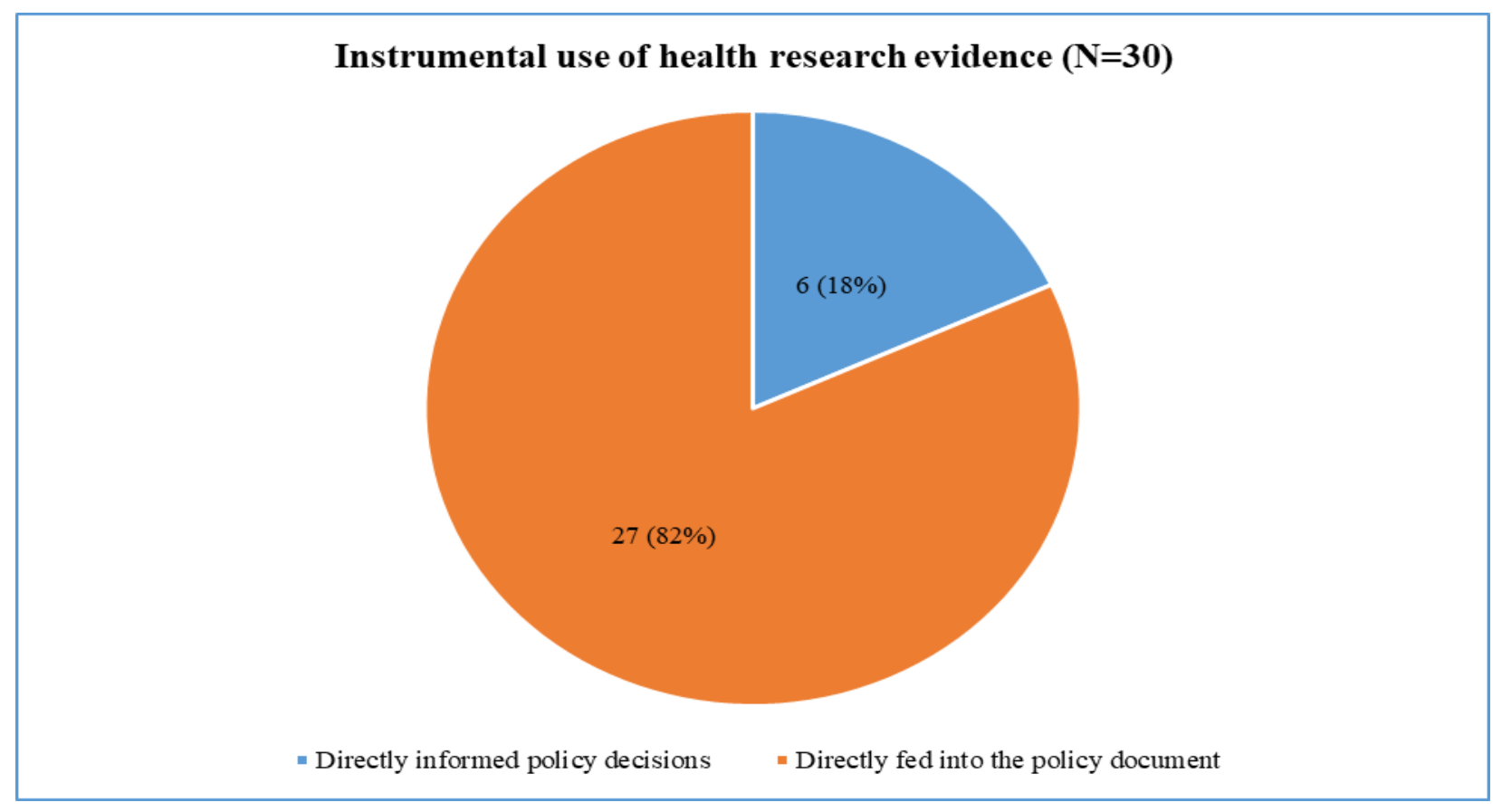

\section{Figure 13: Instrumental use of health research evidence}

In only $6(18 \%)$ of the 30 policy documents health research directly informed policy decisions. In $27(82 \%)$ of the health policy documents, health research evidence fed into the policy documents by way of citing and referencing.

\section{Tactical use of research evidence}

Tactical use of health research evidence gives credibility and trustworthiness to the policy document and persuades stakeholders to support the policy document (Makkar et al., 2016). 
Figure 14 shows how health research evidence has supported health policy formulation in Malawi tactically.

\section{Tactical use of health research evidence $(\mathrm{N}=30)$}

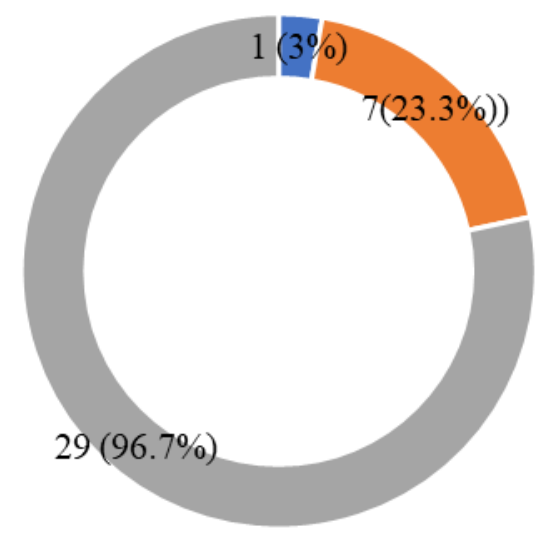

- Provided hard evidence to persuade stakeholders

- Supported an established position, decision, or view

- Informed stakeholders about the key policy issues

\section{Figure 14: Tactical use of health research evidence}

In $29(96.7 \%)$ of the 30 policy documents, health research evidence only informed policy stakeholders of key health policy issues. In only 1 (3\%) of the policy documents health research evidence provided adequate grounds that persuaded stakeholders to support or act upon an existing decision in health policy formulation.

\section{Imposed use of research evidence}

Health research evidence is imposed on a health policy if there are organisational or regulatory requirements to use health research evidence in one way or another (Makkar et al., 2016). This is achieved when organisations encourage the use of health research evidence, and expect research evidence to be used as the best practice or mandates the use of health research every time a policy document is being formulated. Figure 15 shows the imposed use of health research evidence in Malawi. 


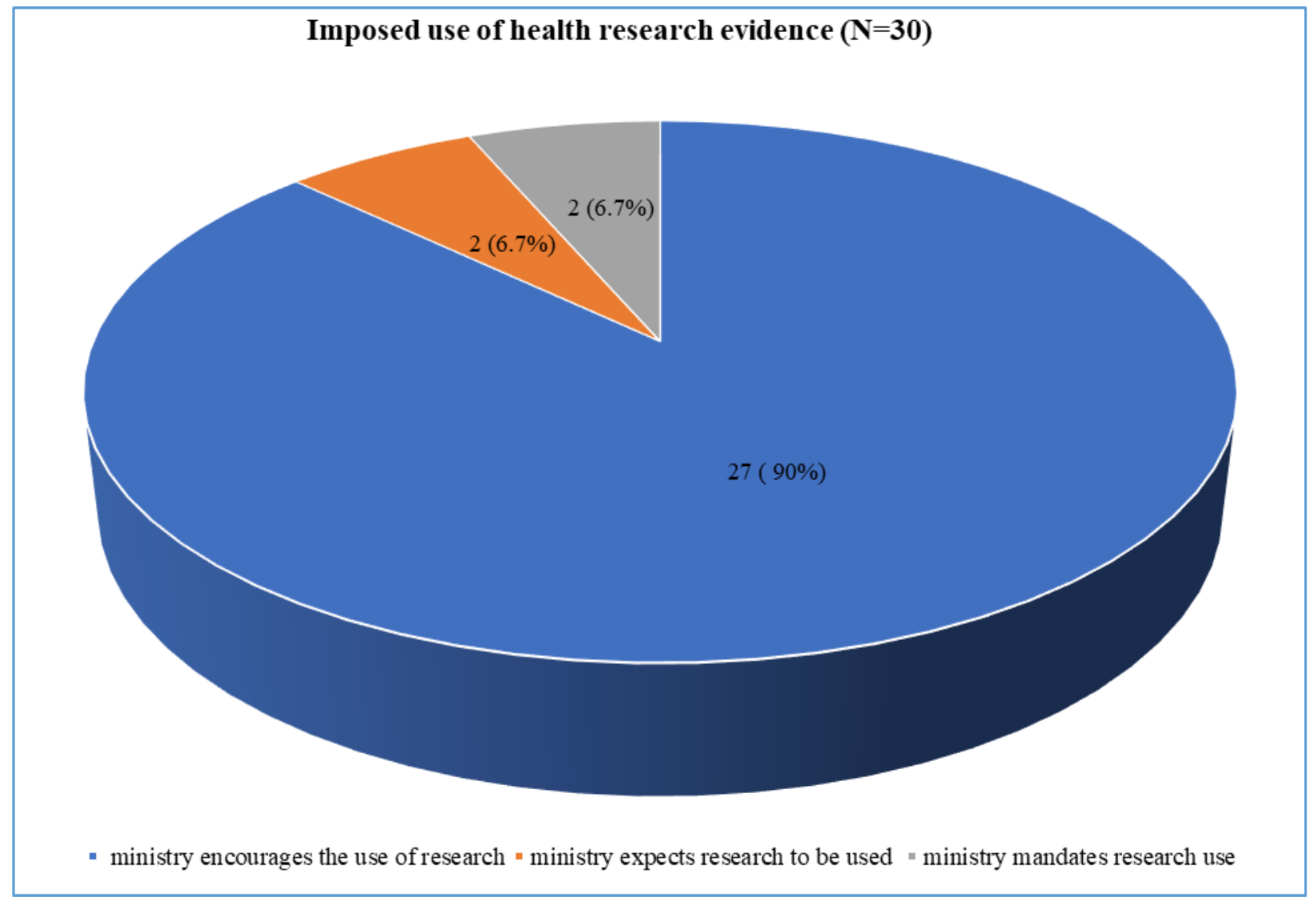

\section{Figure 15: Imposed use of health research evidence}

In $27(90 \%)$ of the 30 policy documents, ministries encouraged the use of health research evidence. In $2(6.7 \%)$ of the policy documents it was an expectation that health research evidence would be used and that it is mandatory to use health research evidence respectively as there are no written regulations imposed to directors at the ministry, healthcare directors and managers.

\section{Barriers to research evidence use}

Barriers to health research use in policy documents emanate from several factors some of which include time, individuals, team agency, political factors, and topical issues (Makkar et al., 2016). Figure 16 shows the degree of barrier impact and the extent to which they impact health research evidence use in policy documents. 


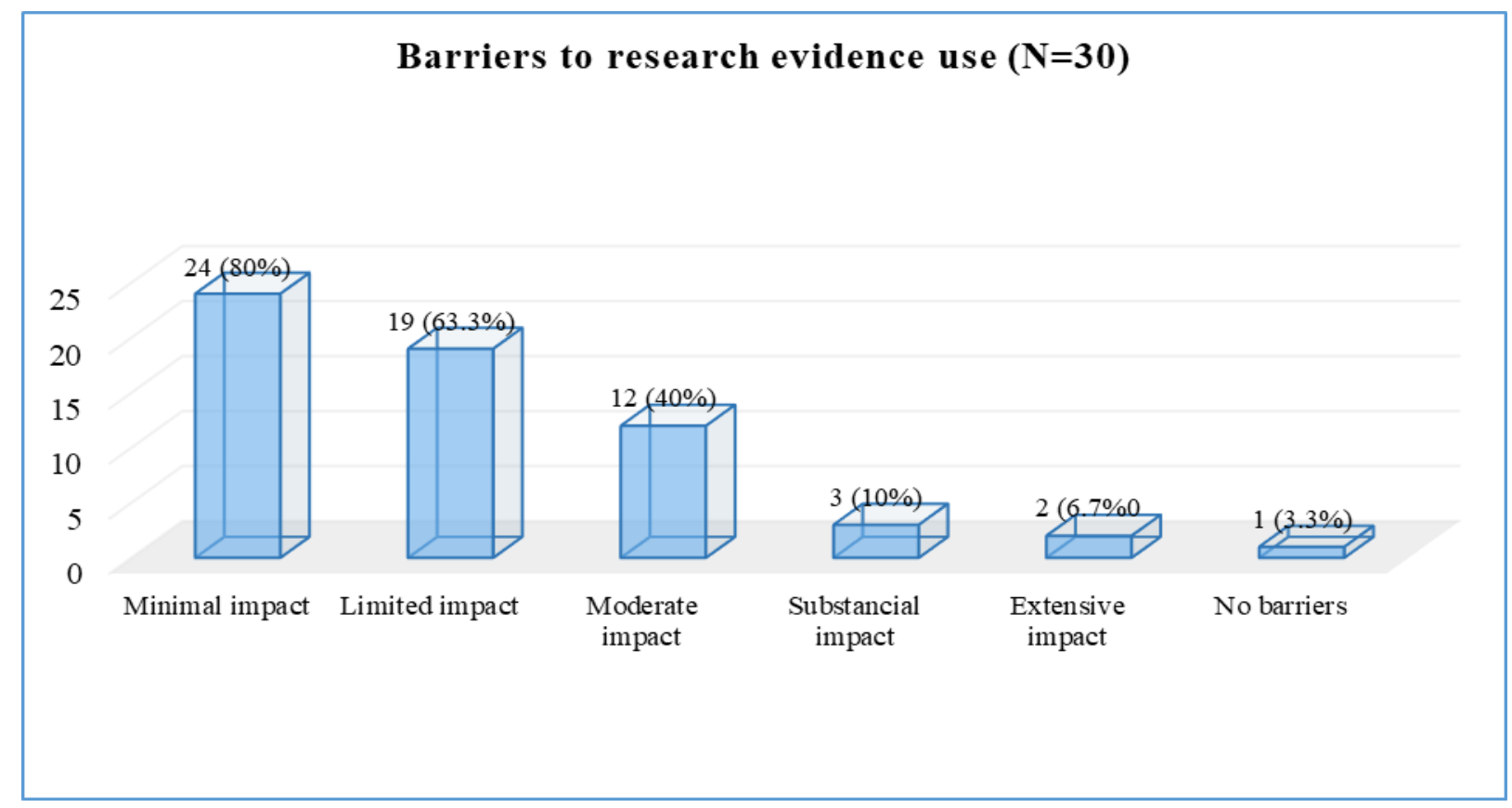

\section{Figure 16: Barriers to health research evidence use}

In only one $(3.3 \%)$ of the 30 health policy documents analysed, there were no barriers to health research evidence use. In $24(80 \%)$ of the health policy documents there was minimal impact of barriers while in only $2(6.7 \%)$ of the policy documents there was extensive impact of barriers as the documents only provided guidelines to be followed when addressing health research issues.

\section{Facilitators of research evidence use in policy formulation}

There are factors that facilitate success in the use of health research evidence in policy formulation. Makkar et al. (2016) identify five such critical factors as including individual skills, team attributes, agency level attributes, political factors and policy topic factors. Figure 17 reflects the five facilitating factors in the use of health research evidence in policy formulation in Malawi. 


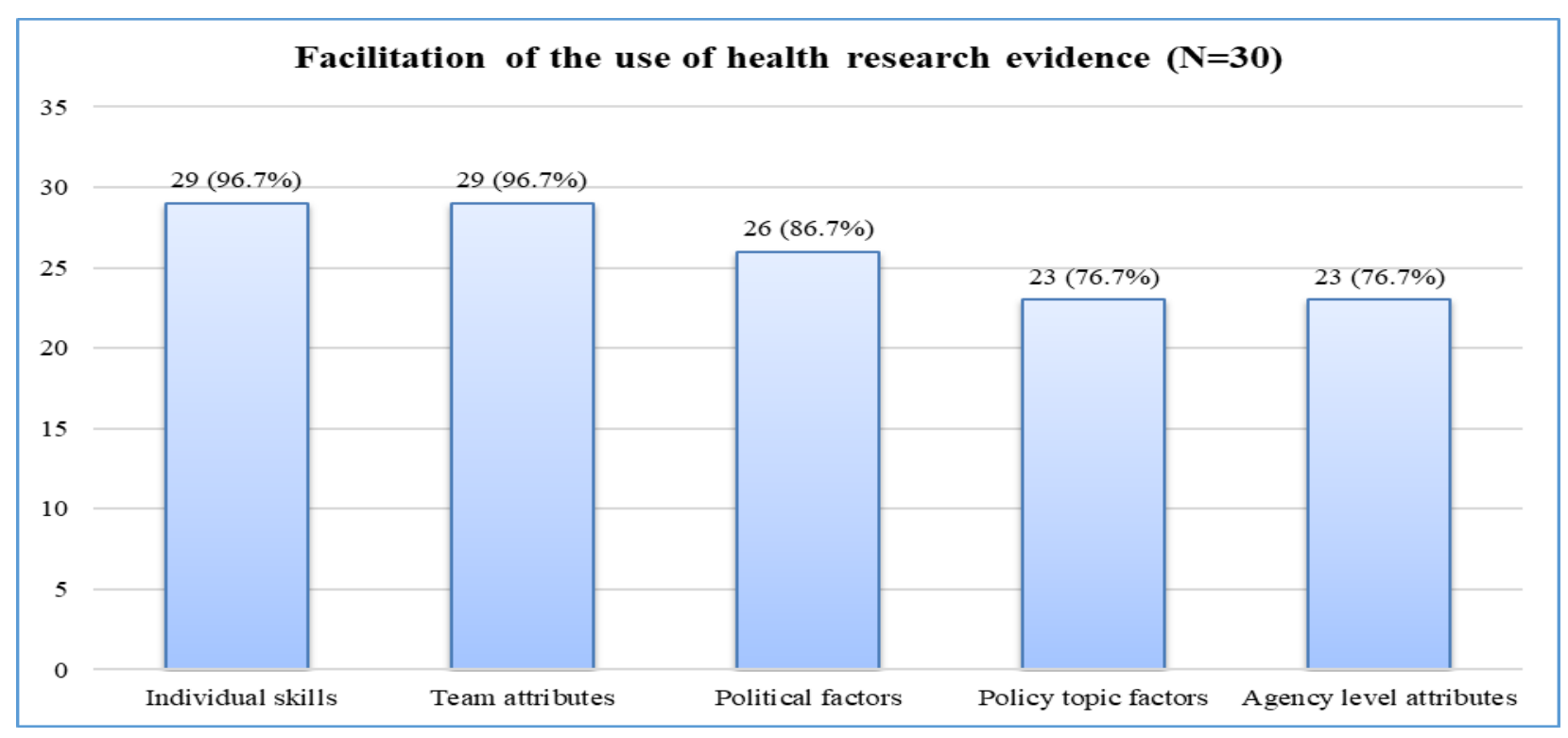

Figure 17: Facilitating attributes to the use of health research in Malawi

Many factors have influenced the way health research evidence is used in health policy formulation. Evidence of both individual and team attributes were found in $29(96.7 \%)$ of the 30 health policy documents.

How research evidence contributed towards the development of the policies

The overall use of health research evidence was used to assess the importance of the contribution of research to policy documents in Malawi. Figure 18 shows the assessment results.

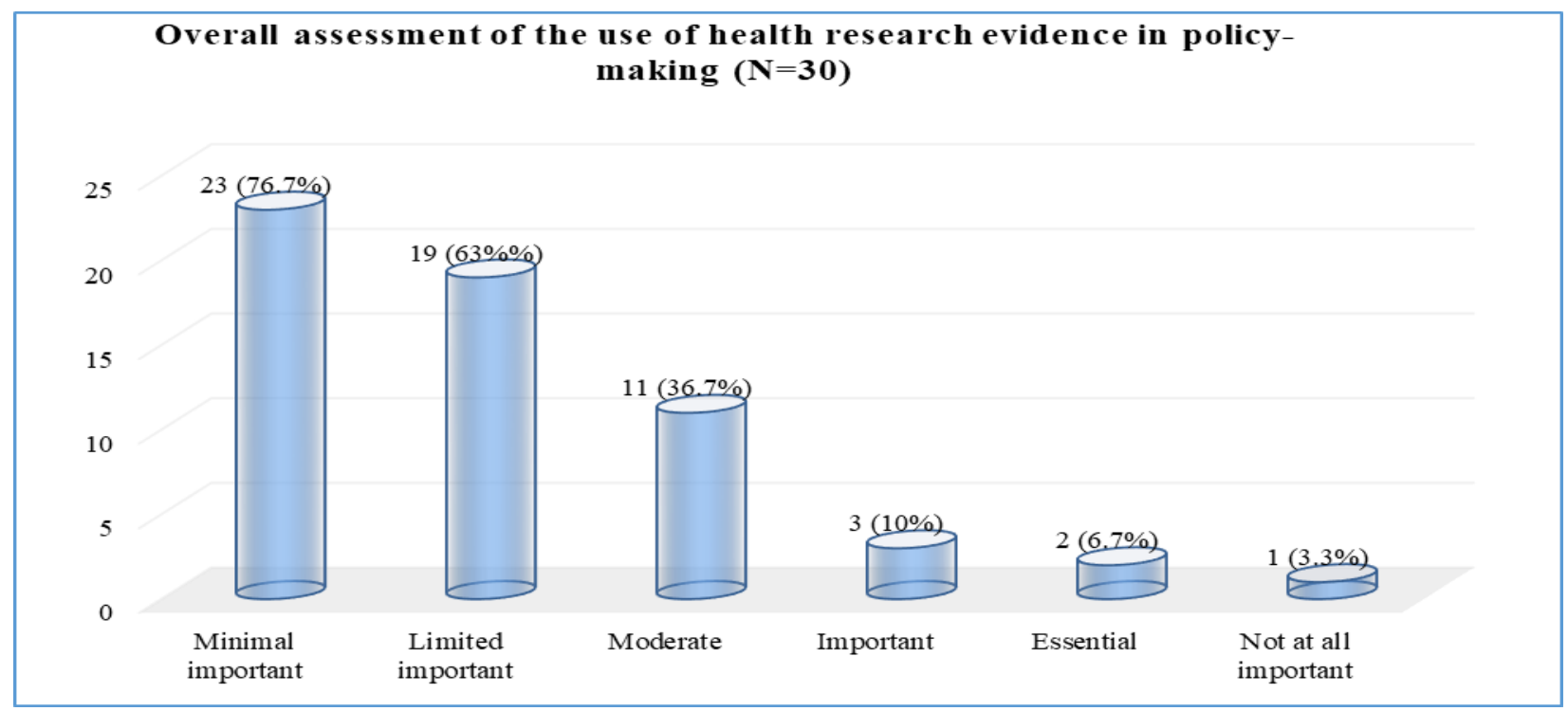

Figure 18: Overall assessment of the use of health research evidence in policy formulation 
Overall in 23 (76.7\%) of the 30 health policy documents analysed, health research evidence played a minimal role and hence had very little influence on the policy document. Similarly, in $19(63.3 \%)$ of the policy documents health research evidence had very little influence on the formulation of the policy documents.

\section{Discussion of the findings}

Public health policies in the health sector in Malawi secure the health of communities, complement wider health coverage and service delivery reforms and are in three categories (WHO, 2018). Firstly, there are systems policies which act as blocks to support universal health coverage and effective service delivery. Secondly, there are public health policies which deal with specific actions needed to address certain priority health problems through prevention and health promotion. Thirdly, there are health policies whose contributions to health are from intersectoral collaboration undertaken by sectors outside the health profession but in collaboration with the health sector, on health issues or health equity outcomes. The following subsection discusses the study findings.

\section{Role of the Ministry in health policy formulation}

In Malawi the role of the Ministry of Health is either central (93.3\%), advisory (86.7\%) or marginal (16.7\%). Research on the role of governments in health policy formulation suggests that health policies are largely based on treaties, negotiations, adoptions and ratifications. Domestic implementation of the treaties do not guarantee achievement of health policies (Hoffman \& Røttingen, 2015: 26-27). Suggestions point to inconsistencies associated with ratification of health-rights treaties and health or social outcomes (Palmer et al., 2009). This suggests that governments sign treaties, but they largely do not go beyond them and do not implement policies based on the available health research evidence and the challenges facing their people.

\section{Methods of allowing research information to inform health policy documents}

The study has revealed that in $96.7 \%$ of the health policy documents, decision makers, directors at the ministry, healthcare directors and managers in Malawi use search engines such as Google to look for health research evidence. Other than that, $93.3 \%$ use grey literature and only $20 \%$ use 
academic literature in a form of journal publications and clinical trials. Studies on the use of search engines allude to the fact that while access to health and medical information has been beneficial to patients, policy and healthcare directors and managers, there is a growing concern that substantial proportions of clinical information on the web is inaccurate, erroneous, misleading, or fraudulent, and poses a threat to public health (McLeod, 1998; Orton et al., 2011).

In a rapid review by Moore, Todd and Redman (2009), 63\% of the health researchers reported to have used one systematic review in every two years. Moore, Todd and Redman further highlighted that $40-50 \%$ of the researchers found that systematic reviews had great influence in decisions around programme justification and planning. Nonetheless, 37-44\% of the health researchers in Moore, Todd and Redman's study indicated that the systematic review did not have any influence on policy development and programme evaluation. Further, regression analysis suggested that the use of health research evidence largely depended on the organisational values.

In the current study, systematic reviews were not identified in the health policies. Only one randomised controlled trial and the use of peer reviewed journals were identified. According to the National Health and Medical Research Council (2009), systematic reviews, appraised evidence of syntheses and guidelines and, peer reviewed journal articles constitute filtered information and are considered as high levels of health research evidence. Similarly, randomised controlled trials, cohort studies, case-controlled reports and expert opinions are rated as low health research evidence and considered as unfiltered information. In the case of health policies in Malawi, it does indicate that low levels of health research evidence are used for health policy formulation.

\section{Types of research found in health documents}

The study revealed that $100 \%$ of the policy-makers in Malawi use reports including evaluations of previous health policies or programmes; $96.7 \%$ use internal data or evaluations within the ministries and $86.7 \%$ use data from ministry registries. Only $20 \%$ of the health policy-makers use primary research in the form of journal articles. Further, only $16.7 \%$ of the health policy documents use secondary research articles such as research summaries. In a study by Ritter 
(2009) in Australia nine sources of research evidence were highlighted: $45.2 \%$ use health research experts; $45.2 \%$ refer to technical reports, monographs and bulletins; $25.8 \%$ access the Internet, specifically Google; $25.8 \%$ use statistical data held by the research and policy units; $22.6 \%$ refer to policy-makers in other jurisdictions such as the National Statistical Offices; $16.1 \%$ consult academic literature; $12.1 \%$ use internal expertise; and, $6.5 \%$ use previous government policies. In another study in Canada, Orton et al. (2011) found that healthcare directors, managers and policy-makers consulted the following sources: $87 \%$ used printed academic literature; $85 \%$ used websites; $66 \%$ used health organisations; and, 64\% used nongovernmental and voluntary organisations. The case in Malawi compares favourably with the Australian case where only $20 \%$ and $16.1 \%$ respectively, use health researched academic literature. The case in Malawi also suggests that policy-makers rely on the Punctuated Equilibrium Model in which the policy process is based on incremental adjustment of the previous health policy evaluations and the use of internal data or data from ministry registries (Cerna, 2013).

\section{Relevance of research found in health documents}

This study has revealed that $83.3 \%$ of the health policies in Malawi were based on data relevant to the Ministry of Health. Most of this data included: health policy evaluations and internal data or registry data from the ministries. Moore, Todd and Redman (2009) suggest that analyses of local information such as routinely collected health data and local evaluations has value in increasing the use of research evidence in policy. However, in the current study in Malawi, there is over usage of internal data from registries in the formulation of health policies at the expense of quality research evidence and data generated through health research in the country.

\section{Assessment of evidence in health policy documents}

Assessment of evidence entails assessing the quality of evidence, its effects on equity, and its applicability in the health policy-making settings (Thornhill, Judd \& Clements, 2009). ImaniNasab et al. (2017) argue that researchers assess the quality of articles with their own knowledge of research methodology; reputation of the journals in which it was published; its impact factors; international reputation of the funding organisation such as WHO; evidence pyramid which 
favours systematic reviews first and the usage of that criteria as evidence to inform policy documents.

In the current study, it has been shown that $96.7 \%$ of the policy documents in Malawi were based on previous health policy documents as applicable to the policy context. Similarly, $16.7 \%$ of the policy assessment indicates that basic research evidence tallied with organisational values and knowledge in which previous health policy evaluations and internal data or data from ministry registries mattered most. Reliance on registry and internal data as opposed to reliable health research evidence has received condemnation especially on where to place studies derived from registries within the hierarchies of health research evidence (Roovers, 2007). Debate centres on the assessment of registry and internal data regarding methods of grading health research evidence, underlying assumptions, shortcomings in assessing types of evidence and consistency in evaluating the evidence itself (Blommestein, Franken \& Uyl-de Groot, 2015).

\section{Quality of health research evidence in policy documents}

Research documents examining the levels of quality of health research documents show a limited number of studies on the topic. Quality of health research evidence considers the sample size sufficiency, methods of collecting data and how threats to validity were addressed (Makkar et al., 2016). In this study, it has been observed that high quality research information from peer reviewed journals to randomised controlled trials only constituted 9\%. Moderate health researched evidence comprising of reports from the National Statistical Office and other government agencies only contributed $7 \%$ while data from registries and previous internal policies contributed $44 \%$ of the health research evidence.

Zardo and Collie (2014) in their research in Australia found out that out of 50 references to health research evidence and $23.4 \%$ of the health policies examined on compensable injuries, health research evidence in a form of peer reviewed journal articles had the least sources of health research evidence. There were more references supporting claims in decision making by healthcare directors and managers than in support of policy information. The study concluded that $47.5 \%$ were significant references to internal policies of unresearched information; $21.8 \%$ were clinical reports; $8.5 \%$ were internal legislation of unresearched information; $10.3 \%$ were external policies; and, $2.4 \%$ were legislative documents. Comparatively, the current study shows 
that in Malawi the Ministry of Health relies on previous internal policies as sources of health research evidence. Accordingly, such sources of information constitute unfiltered information and in the hierarchy of health research evidence they are considered as low sources of health research evidence and therefore unreliable (National Health and Medical Research Council, 2009).

\section{Procedures in health policy formulation}

Health policies are formulated by personnel at various levels including directors at the ministry, healthcare directors and managers. In this study, $93.3 \%$ of the health policies were formulated by consultants or experts some of which are directors at the ministry, healthcare directors and managers assembled by the ministry policy units; $10 \%$ were through a structured appraisal guideline adopted from previous guidelines; 3.3\% were from a predefined strategy such as a previous policy guidelines; while $13.3 \%$ were from a team that included directors at the ministry, healthcare directors and managers assembled as an adhoc committee. Many players influence policy formulation, including civil society organisations, political influences as well as the donor community. WHO (2009) argues that because of the conflict between various health policymakers many health policies are old and only wear 'new clothes' meaning; firstly, the policies are path works of subsector components often formulated by vertical programmes; secondly, the policies are poorly integrated into the framework while neglecting important ideas; thirdly, the policies are sketched under pressure because of donor support; fourthly, the policies are

formulated with international pressure, obligations and expectations in order to project a broad and positive image of the health sector.

\section{Methods of soliciting research evidence in health documents}

The study has shown that $66.7 \%$ of the health policies are appraised based on author or source credibility; 96.7\% are appraised based on expert assessment some of which are directors at the ministry, healthcare directors and managers; only $6.7 \%$ are appraised based on research designs. WHO (2009) observed that in most cases health policies are blue printed from international models by health experts including directors at the ministry, healthcare directors and managers brought by aid agencies. WHO (2009) also noted that some health policies are formulated by 
prominent insiders (academics, researchers, healthcare directors and managers) with high profiles despite their overambitious goals and technical drawbacks.

In the current study, many policies in Malawi were formulated by a team of health policy and decision makers (directors at the ministry, healthcare directors, managers, nursing managers, medical practitioners) and the academia by invitation. However, while this is the model in most of the health policies in Malawi, the levels of health research evidence used in the health polices is very low and unreliable. The Ministry of Health relies on registry data and internal evaluations of previous health policies. The Ministry of Health also relies on data from the National Statistical Office. This indirectly suggests that health researchers invited to participate in health policy formulation do not take advantage of their presence during policy formulation and health research evidence available from various studies undertaken to articulate the usefulness of peer reviewed health research evidence in health policy formulation.

\section{Type of personnel involved in health policy formulation}

This study in Malawi shows some intersection of various players in policy formulation. For example, $96.7 \%$ of health policies in Malawi were formulated by internal members including directors at the ministry, healthcare director, district health officers, nursing managers and other medical practitioners within the ministries; $83.3 \%$ involved an evaluative team specifically set for the policy; $80 \%$ of them involved setting up a working group; and, $13.3 \%$ involved health researchers. The current study shows that as much as the interaction between health researchers, policy-makers, healthcare directors, managers and district health officers exist in Malawi, it has not translated into the transfer of health research evidence into health policy formulation. The two worlds of researchers and policy-makers are still apart from each other and the use of health research evidence in policy-making or formulation is superficial.

Evidently, Hawkes et al. (2015) in an assessment of health policy-makers in Bangladesh, Nigeria, Gambia and India, observed that most of the health researchers pursued their own interests; had poor communications skills; their research outputs were irrelevant to the national needs; they lacked centralised sites for accessing information; and few, had opportunities for interacting with health policy-makers. On the other hand, directors at the ministry, healthcare 
managers, directors and nursing managers were poorly capacitated to interpret and use health research data.

\section{How research informed the development of the policy documents}

This study has shown that conceptually, 30\% of the health research in Malawi has informed the thinking about the background to the health policy issue; $93.3 \%$ of the research has helped policy-makers understand the policy context; $76.7 \%$ of the research suggested policy priorities; while only $30 \%$ helped in policy evaluation. Instrumentally, only $18 \%$ of the health research evidence directly informed health policy decision while $82 \%$ was only used to feed into the policy document as supporting statements to be cited and referenced. Tactically, this research has shown that $78 \%$ of the health research use is to inform policy stakeholders of key policy issues; $19 \%$ supports an established position, decision or view; and only $3 \%$ of the policy documents

provide adequate research evidence that could persuade stakeholders to support an existing decision or view about health policy formulation. Internationally, there is a growing pressure on using health research evidence to improve decision making and this requires access to evidence as well as the capacity to use the research evidence. Research in Africa and Asia by Rodríguez et al. (2017) show that South Africa and Zambia have high levels of organisational capacity to use health research evidence, while Pakistan and Bangladesh have the lowest organisational capacity to use health research evidence. In contrast, it was also noted that individual capacity was the highest in Pakistan and South Africa while the lowest in Bangladesh and Lebanon in terms of health research evidence use in policy formulation.

\section{Barriers to research evidence use}

This study has shown that $3.3 \%$ of the health policy documents showed the directors at the ministry, healthcare directors and managers in central and district hospitals had no barriers to health research evidence; $80 \%$ faced minimal barriers while $6.7 \%$ faced some barriers as the documents provided only guidelines to be followed when addressing health research issues. Oliver et al. (2014) in their systematic review found that barriers to health evidence uptake were largely due to poor access to quality and relevant research, and lack of timely research output. Wallace, Nwosu and Clarke (2012) identified lack of use, awareness, limited access, familiarity, and lack of perceived usefulness as barriers to health research evidence uptake. Murthy et al. 
(2011) suggest that barriers to health research usage is exacerbated by the enormous volume of health research evidence, and the difficulties in applying global health research evidence in a local clinical context where healthcare directors and managers are based. Orton et al. (2011) in a study in Kenya and Malawi noted that barriers to the use of research evidence include: policymakers including healthcare directors and managers' perceptions of the health research evidence as inadequate to address their needs; lack of interaction and existence of a gap between health researchers and policy-makers, healthcare directors and managers; the context and culture in which policy-makers, healthcare directors and managers work; and, competing influences between health research and policy-making.

\section{Facilitators of research evidence use}

This study has shown that $96.7 \%$ of the individual's skills count for the use of health research evidence and team attributes, respectively. Apart from individual attributes, $86.7 \%$ were based on political factors supporting the use of health research evidence while $76.7 \%$ were dictated by the policy topic factors. Oliver et al. (2014), in their systematic review, contrarily observed that health evidence uptake was largely due to firstly, collaboration between researchers and policymakers healthcare directors and managers; and, secondly, improved relationships and skills. Orton et al. (2011) further argue that facilitators of health research evidence should firstly be targeted at the needs of policy-makers, healthcare directors and managers; secondly, health research should highlight key messages; and thirdly, there is need to build health research capacity between health researchers, policy-makers, healthcare directors and managers.

\section{Conclusion}

The Ministry of Health plays a central role in health policy formulation in Malawi. The Ministry does not use health research evidence in a form of systematic reviews as appropriate source of health research evidence. Instead the Ministry relies on internal data from its registry or evaluation of the previous policies. The levels and quality of health research evidence used in health policy formulation is very low on the hierarchy of health research evidence in which systematic reviews are considered as the highest level of research evidence and expert opinions are considered as the lowest levels of health research evidence. While some health researchers are invited during health policy formulation, their presence in the policy planning teams has not contributed to the improved use of high quality research evidence in policy formulation. The use 
of health research evidence in health policy formulation in Malawi is therefore superficial and deliberate efforts should be put in place to utilise high levelled research evidence to inform health policy-making.

\section{Acknowledgements}

The researcher wishes to acknowledge funding support from the University of Cape Town Incoming International Student Award.

\section{References}

African Health Observatory Online (2015), 'Use of information, evidence or knowledge', available at: http://www.aho.afro.who.int/profiles_information/index.php/Malawi:Index (accessed 5 October 2015).

Andermann, A., Pang, T., Newton, J.N., Davis, A. \& Panisset, U. (2016), ' Evidence for health II: overcoming barriers to using evidence in policy and practice', Health Research Policy and Systems, Vol. 14 No 1, pp. 1-7.

Davis, D. (2006), "Continuing education, guideline implementation, and the emerging transdisciplinary field of knowledge translation', The Journal of Continuing Education in the Health Professions, Vol. 26 No 1, pp. 5-12.

Bartunek, J., Trullen, J., Bonet, E. \& Sauquet, A. (2003), “Sharing and expanding academic and practitioner knowledge in health care', Journal of Health Services Research and Policy, Vol. 8 No. 2, pp. 62-68.

Bowen, G.A. (2009), “Document analysis as a qualitative research method', Qualitative Research Journal, Vol. 9 No. 2, pp. 27-40.

Bowen, S.J. \& Graham, I.D. (2013), “From knowledge translation to engaged scholarship: promoting research relevance and utilization', Archives of Physical Medicine and Rehabilitation, Vol. 94 No. 1, pp. S3-S8.

Brehaut, J. \& Eva, K. (2012), “Building theories of knowledge translation interventions: use the entire menu of constructs", Implementation Science. Vol. 7 No. 114, pp. 1-10.

Blommestein, H.M., Franken, M.G \& Uyl-de Groot, C.A. (2015), “A practical guide for using registry data to inform decisions about the cost effectiveness of new cancer drugs: lessons learned from the PHAROS registry', Pharmacoeconomics, Vol. 33 No 6, pp. 551-560.

Cerna, L. (2013), The nature of policy change and implementation: a review of different theoretical approaches, Organisation of Economic Co-operation and Development, Rome.

Graham, I.D. \& Tetroe, J. (2007), "How to translate health research knowledge into effective healthcare action', Healthcare Quarterly, Vol. 10 No. 3, pp. 20-22. 
Grol, R. \& Grimshaw, J. (2003), “From best evidence to best practice: effective implementation of change in patients' care', Lancet, Vol. 362 No. 9391, pp. 1225-1230.

Hawkes, S., K Aulakh, B., Jadeja, N., Jimenez, M., Buse, K., Anwar, I., Barge, S., Odubanjo, M.O., Shukla, A., Ghaffar, A. \& Whitworth, J. (2015). ' Strengthening capacity to apply health research evidence in policy-making: experience from four countries', Health Policy and Planning, Vol. 31 No. 2, pp. 161-170.

Hoffman, S.J. \& Røttingen, J.A. (2015), “Assessing the expected impact of global health treaties: evidence from 90 quantitative evaluations', American Journal of Public Health, Vol. 105 No. 1, pp. 26-40.

Imani-Nasab, M.H., Seyedin, H., Yazdizadeh, B. \& Majdzadeh, R. (2017), “'A qualitative assessment of the evidence utilisation for health policy-making on the basis of SUPPORT tools in a developing country', International Journal of Health Policy and Management, Vol. 6 No. 8, pp. 457-465.

International Monetary Fund Online. (2017). Malawi economic development document, International Monetary Fund, Washington, DC.

Kirigia, J.M., Kathyola, D.D., Muula, A.S. \& Ota, M.M.O. (2015), “'National health research system in Malawi: dead, moribund, tepid or flourishing?', BMC Health Services Research, Vol. 15 No. 6, pp. 1-14.

Lavis, J.N., Ross, S.E., Hurley, J.E., Hohenadel, J.M., Stoddart, G.L. \& Woodward, C.A. (2002), "Examining the role of health services research in public policy-making', The Milbank Quarterly, Vol. 80 No. 1, pp. 125-154.

Lavis, J.N., Catallo, C., Permanand, G. \& Zierler, A. (2013), Communicating clearly: enhancing information-packaging mechanisms to support knowledge brokering in European health systems, European Observatory on Health Systems \& Policies, Brussels:

Makkar, S.R., Brennan, S., Turner, T., Williamson, A., Redman, S. \& Green, S. (2016), “The development of SAGE: a tool to evaluate how policymakers engage with and use research in health policy-making', Research Evaluation, Vol. 25 No. 3, pp. 315-328.

Moore, G., Todd, A. \& Redman, S. (2009), Strategies to increase the use of evidence from research in population health policy and programs: a rapid review, The Sax Institute, New South Wales.

Murthy, L., Shepperd, S., Clarke, M., Garner, S.E., Lavis, J.N. \& Roberts, N.W. (2011), "Interventions to improve the use of systematic reviews for clinical and commissioning decision-making', Cochrane Database Systematic Review. Vol. 10, pp. 1-23.

National Institutes of Health. (2014), “Budget, National Institutes of Health', available at: https://www.nih.gov/about-nih/what-we-do/budget (accessed 2 May 2017). 
National Health and Medical Research Council. (2009), "NHMRC levels of evidence and grades for recommendations for developers of clinical practice guidelines" available at: https://www.nhmrc.gov.au/_files_nhmrc/file/guidelines/developers/nhmrc_levels_grades_eviden ce_120423.pdf (accessed 18 June 2018).

O'Leary, Z. (2014), The essential guide to doing your research project, $2^{\text {nd }}$ ed, Sage, Thousand Oaks, CA.

Oliver, K., Innvar, S., Lorenc, T., Woodman, J. \& Thomas, J. (2014), “'A systematic review of barriers to and facilitators of the use of evidence by policymakers", BMC Health Services Research, Vol. 14 No. 1, pp. 2-12.

Orton, L., Lloyd-Williams, F., Taylor-Robinson, D., O'Flaherty, M. \& Capewell, S. (2011), "The use of research evidence in public health decision making processes: systematic review", PloS One, Vol. 6 No. 7, pp. 1-10.

Parkhurst, J. (2017), The politics of evidence: from evidence-based policy to the good governance of evidence, Routledge, Oxford.

Palmer, A., Tomkinson, J., Phung, C., Ford, N., Joffres, M., Fernandes, K.A., Zeng, L., Lima, V., Montaner, J.S., Guyatt, G.H. \& Mills, E.J. (2009), "Does ratification of human-rights treaties have effects on population health?”, The Lancet, Vol. 373 No. 9679, pp. 1987-1992.

Redman, S., Turner, T., Davies, H., Williamson, A., Haynes, A., Brennan, S., Milat, A., O'Connor, D., Blyth, F., Jorm, L. \& Green, S. (2015), “The SPIRIT Action Framework: a structured approach to selecting and testing strategies to increase the use of research in policy", Social Science and Medicine, Vol. 136, pp. 147-155.

Ritter, A. (2009), “'How do drug policy-makers access research evidence?”, International Journal of Drug Policy, Vol. 20 No. 1, pp. 70-75.

Rodríguez, D.C., Hoe, C., Dale, E.M., Rahman, M.H., Akhter, S., Hafeez, A., Irava, W., Rajbangshi, P., Roman, T., Ţîrdea, M. \& Yamout, R. (2017), "Assessing the capacity of ministries of health to use research in decision-making: conceptual framework and tool", Health Research Policy and Systems, Vol. 15 No. 1, pp. 65-77.

Roovers, J.P.W. (2007), “Registries: what level of evidence do they provide?', International Urogynecology Journal, Vol. 18 No 10, pp. 1119-1120.

Schryer-Roy, A.M. (2005). "Knowledge translation: basic theories, approaches and applications", International Development Research Centre, Vol. 4 No. 12, pp. 1-12.

Statistical Portal Online. (2018), "Malawi: gross domestic product in current prices from 2012 to 2022" available at: https://www.statista.com/statistics/520530/gross-domestic-product-gdp-inmalawi/ (accessed 26 June 2018). 
Sussman, S., Valente, T.W., Rohrbach, L.A., Skara, S. \& Pentz, M.A. (2006), "Translation in the health professions converting science into action', Evaluation and the Health Professions, Vol. 29 No. 1, pp. 7-32.

Thornhill, J., Judd, M. \& Clements, D. (2009), “CHSRF knowledge transfer: (re)introducing the self-assessment tool that is helping decision-makers assess their organisation's capacity to use research', Healthcare Quarterly, Vol. 12 No. 1, pp. 22-24.

Wallace, J., Nwosu, B. \& Clarke, M. (2012), “'Barriers to the uptake of evidence from systematic reviews and meta-analyses: a systematic review of decision makers' perceptions', British Medical Journal Open, Vol. 2 No. 5, pp. 1-14.

Walshe, K. \& Rundall, T.G. (2001), “Evidence-based management: from theory to practice in health care', The Milbank Quarterly, Vol. 79 No. 3, pp. 429-457.

World Health Organisation. (2004), The Mexico statement on health research: knowledge for better health: strengthening health systems, World Health Organisation, Geneva, Switzerland.

World Health Organisation. (2008), The Bamako call to action on research for health:

strengthening research for health, development, and equity from the global ministerial forum on research for health. World Health Organisation, Bamako, Mali.

World Health Organisation. (2009), Analysing disrupted health sectors. World Health Organisation, Geneva, Switzerland.

World Health Organisation. (2012), Knowledge translation framework for ageing and health. World Health Organisation, Geneva, Switzerland.

World Health Organisation. (2018), “2018 General country health policies", available at: http://www.aho.afro.WHO.int/en. (accessed 27 February 2018).

Zardo, P. \& Collie, A. (2014), " Measuring use of research evidence in public health policy: a policy content analysis”, BMC Public Health, Vol. 14 No. 1, pp. 496-506. 